\title{
Environmental Tax Reform and Income Distribution with Imperfect Heterogeneous Labour Markets
}

\author{
Diane Aubert*and Mireille Chiroleu-Assouline ${ }^{\dagger \ddagger}$
}

March 19, 2019

\begin{abstract}
This paper investigates the distributional and efficiency consequences of an environmental tax reform that distributes the revenue from a green tax according to varying labour tax rates. We build a general equilibrium model with heterogeneous workers, imperfect labour markets (search and match), and pollution consumption externalities. Preferences are non-homothetic (Stone-Geary utility) to take into account the potential regressivity of green taxes (the polluting good is assumed to be a necessary good). If the reform appears regressive, the gains from the double dividend can achieve Pareto improvement, using a redistributive non-linear income tax if the redistribution is not too great initially. Increasing progressivity influences the unemployment rate and can moderate the tradeoff between equity and efficiency. We finally provide numerical illustrations for France and conduct sensitivity analysis.

JEL classification: D62 - D63 - H23 - Q52 - Q58.
\end{abstract}

Keywords: Environmental tax reform - Heterogeneity - Unemployment - Welfare analysis - Tax progressivity

${ }^{*}$ CER-ETH, Center of Economic Research at ETH Zurich, ZUE F15, Zurichbergstrasse 18, CH-8092 Zurich, Switzerland. Email: daubert@ethz.ch

${ }^{\dagger}$ Corresponding author. Paris School of Economics and Université Paris 1 - Panthéon Sorbonne, 48 bd Jourdan-75014 Paris. Email: Mireille.Chiroleu-Assouline@univ-paris1.fr

${ }^{\ddagger}$ UMR Economie Publique, AgroParisTech, INRA, Université Paris Saclay, 78850 Thiverval-Grignon, France. 


\section{Introduction and Literature Review}

Can the use of environmental taxes still be advocated in an era characterized by secular stagnation, persistent unemployment and increased inequality? As is true of all indirect taxation, environmental taxes (e.g., carbon taxes) lower consumers' purchasing power and tend to be strongly regressive, harming poor consumers more than rich ones, because polluting goods are often necessities, such as energy for transportation or heating. Such a situation can easily limit growth and extend stagnation because the propensity to consume decreases with income (Summers, 2015). Despite growing awareness of the need to reduce greenhouse gas emissions to fight climate change, governments are often reluctant to implement green tax shifts for fear of strong opposition from the public. ${ }^{1}$

We take the opposite view of this wide-spread argument. We argue that green tax shifts may be appropriate policies both to limit the ongoing climate change, and to boost employment and welfare, without widening inequalities.

In particular, green tax shifts that redistribute the revenues raised by green taxes by reducing the rates of distortionary taxes (e.g., labour taxes), might yield a double dividend: an environmental dividend, by improving the environment; and an economic dividend, by achieving an increase of non-environmental welfare due to the greater efficiency of tax system (we refer to the strong form of double dividend; Goulder, 1995).

Starting with Bovenberg and de Mooij (1994), extensive theoretical and empirical literature has detailed the conditions that favour the emergence of a double dividend. ${ }^{2}$ The latter is more likely to occur when there are market failures (like imperfect competition), and several productive factors or consumers' groups. In particular, it seems that non-competitiveness of the labour market and the occurrence of (involuntary) unemployment enhance the possibility of a double dividend (Goulder, 1995). ${ }^{3}$ Indeed, there is more scope to shift the tax burden from an overtaxed factor (labour, i.e. wage earners) to under-taxed factors or other consumers (as unemployed workers, or retirees). It nevertheless underlines the potential trade-off between economic efficiency and equity: Recycling the revenue of pollution taxes may be efficient but could also exacerbate the regressivity of green taxes (Fullerton and Monti, 2013; Williams et al., 2015). Therefore, governments face an essential dilemna in designing environmental fiscal

\footnotetext{
${ }^{1}$ Only Sweden implemented a significant budget-neutral environmental tax reform in the 1990s. The carbon tax is for years discussed in terms of poor vs. rich inequality in France (Combet et al., 2010; Laurent, 2011) and recently caused the demonstrations of the "Yellow Vests". In Ireland, first attempts to introduce a carbon tax in 2004 were abandoned partly due to distributional concerns (Callan et al., 2009).

${ }^{2}$ Bovenberg and de Mooij (1994) highlight the trade-off between both dividends: Green taxes incite to substitute between polluting and non-polluting goods, as well as between work and leisure, due to the loss of purchasing power. It results in a tax base erosion (the raise in green taxes reduces the labour taxes revenue), that may counteract the economic dividend. Parry (1995) gives the conditions for an economic dividend: The revenue recycling effect that reduces the existing tax distortions must be greater than the tax interaction effect that provides tax base erosion. See also Terkla (1984), Poterba (1991), Proost and Van Regemorter (1995), Bovenberg (1999), and Ekins (1997).

${ }^{3}$ Among others, Bovenberg and van der Ploeg (1996), Bovenberg and van der Ploeg (1998), Schneider (1997), Koskela and Schöb (1999), and Bayındır-Upmann and Raith (2003) analyse the double dividend issue with unemployment.
} 
reforms with a distributive objective, without losing the efficiency advantage of green taxes.

In response to this situation, we investigate the distributional and efficiency consequences of revenueneutral environmental tax reforms with unemployment. To the best of our knowledge, this study is the first to address the fairness of environmental tax reforms by modelling heterogeneous, imperfect labour markets.

We build a general equilibrium model with heterogeneous workers, imperfect labour markets, and pollution consumption externalities. There are two different types of households, which differ via their labour skills (low or high-skilled) and earn wages accordingly. We use a search and matching model (Pissarides, 2000) to include structural unemployment caused by hiring costs. By assumption, the risk of unemployment falls only on low-skilled workers, whose labour supply is inelastic, whereas the highskilled labour supply is endogenous. Pollution is due to the consumption of a polluting ("dirty") good. For accounting for the potential regressivity of green taxes, we use Stone-Geary preferences (i.e., nonhomothetic preferences): Poor households may spend relatively more on polluting goods than do rich ones. The tax system is initially composed of a progressive labour tax (tax on wages). We consider a secondbest setting consistent with literature on the double dividend. The model is fully solved analytically. We characterize the necessary conditions for the double dividend and study the distributive properties of the tax reform, when the green taxes revenue is recycled by adjusting the labour tax rates and their progressivity index.

Even in a case in which a green tax reform appears regressive, using a non-linear (or progressive) income tax affects unemployment and can moderate the trade-off between equity and efficiency. The gains from the double dividend can become Pareto improving if the initial redistribution and wage elasticity of the high-skilled labour supply are not too great, because the cost of progressivity in terms of reducing high-skilled labour supply would be more than compensated for by the low-skilled employment effect. Finally, we illustrate our results through a calibration of our model for France.

Some related literature already has considered the distributional incidence of green taxes, without reaching a consensus. Early empirical studies on developed countries estimate that green taxes are strongly regressive. ${ }^{4}$ They highlight a uses side of income effect (as named by Fullerton and Monti, 2013), that reflects the fact that poor households seem to devote a larger part of their income to polluting goods. But recent works question such result because of the methodology used. Environmental taxes are empirically estimated less regressive and even progressive, when using another measure of income effect (Sterner, 2012; Cronin et al., 2017). Besides, general equilibrium models stress the significant impact of green taxes on the income formation of households (on the sources sides of income), through factor

\footnotetext{
${ }^{4}$ See Poterba (1991), Metcalf (1999), Metcalf (2009), West and Williams III (2012) for empirical estimation of the regressivity of green taxes in the U.S; Wier et al. (2005) for Denmark; Ruiz and Trannoy (2008) for France. Our results, as well as our analysis, are relevant mainly for developed economies, because carbon taxes seem rather progressive for developing countries (Sterner, 2012).
} 
prices change, as relative wage or capital revenue. This could favour progressivity (Rausch et al., 2011; Dissou and Siddiqui, 2014; Mathur and Morris, 2014). Finally, micro-simulation models show that results depend mainly on the way the green tax revenue is recycled. The overall reform appears less regressive, or progressive, if the government uses the green tax revenue for providing lump-sum transfers (Cronin et al., 2017; Douenne, 2018; Berry, 2019). ${ }^{5}$ However, it might not be efficient (Williams et al., 2015). ${ }^{6}$

We contribute to this debate, addressing both equity and efficiency issues of green tax reforms, in a theoretical framework. Few papers are closely related to ours. In a general equilibrium model, with heterogeneous workers, Fullerton and Monti (2013) study a green tax reform that reduces labour tax rates. They show that if the dirty sector is low-skilled labour intensive, green taxes reduce the relative wage of low-skilled workers. Labour tax rebates do not succeed to compensate them. Yet, their full competition assumption does not allow a double dividend. Chiroleu-Assouline and Fodha (2011) and Chiroleu-Assouline and Fodha (2014) use an overlapping-generations framework with inter and intra-generational heterogeneities. They show that using the progressivity of labour taxes allows to re-design a recycling mechanism that renders the tax reform Pareto-improving. However, they assume inelastic labour supply and full employment. Few theoretical works already introduced non-homothetic preferences, accounting for the potential regressivity of green taxes. Klenert and Mattauch (2016), with Stone-Geary preferences, analyse the distributive properties of different recycling options. In an optimal tax framework, Jacobs and van der Ploeg (2019) build on Jacobs and de Mooij (2015) by adding nonhomothetic preferences. They show that the environmental tax reform may improve social welfare, without deteriorating inequalities, if the government can use lump-sum transfers, besides labour taxes. But their partial equilibrium framework relies on perfect competition assumption. Finally, similar to us, Hafstead and Williams (2018) analyse a green tax shift in a general-equilibrium model with search and matching to model unemployment. They study the long-term dynamics of unemployment through a sector analysis but do not consider inequalities. We prefer to deal with heterogeneous labour markets behaviour in a static model, which allows us to obtain analytical solutions.

Our paper extends this literature by combining two major assumptions that supposedly are detrimental to equity. First, heterogeneous households require some subsistence level of polluting goods. Second, the labour market is characterised by an endogenous labour supply and unemployment. With our model, we can analyse the green taxes' effects on labour revenue (sources side of income) without neglecting the uses side of income. To keep the model tractable analytically, we do not integrate a sector analysis;

\footnotetext{
${ }^{5}$ Cronin et al. (2017) study vertical equity - i.e. distributive effects between households with different incomes - and horizontal equity - i.e. distributive effects between households with similar incomes - of environmental tax reforms. They use households' expenditures as a measure of the income effect and find tax green shifts progressive. Douenne (2018) provides a similar analysis for France, but also estimates price elasticities for energy products and introduces substitution effects.

${ }^{6}$ Combining a general equilibrium model with a micro-simulation one, Williams et al. (2015) show that using green tax revenue to cut capital taxes appears the most effective reform for the U.S., but increases inequalities. Returning the revenue via lump-sum transfers has opposite results.
} 
as in Bovenberg and de Mooij (1994), Schneider (1997), and Koskela and Schöb (1999), pollution is caused by the consumption of the dirty good that we assume is produced with the same technology a the clean good. Sector analyses by Fullerton and Monti (2013), and Hafstead and Williams (2018) thus can complement this study. Accordingly, by analysing how labour market features and a minimum level of polluting consumption may influence the efficiency and equity of environmental tax reforms, we make three main contributions.

First, we allow for non-perfect substitution of heterogeneous labour with a consideration of unemployment. Low-skilled workers choose to participate to the labour market knowing that they may be employed or unemployed. High-skilled workers choose their hours of work. We model extensive margin decisions for the former, and intensive margin decisions for the latter, which reveals key insights into the difference between high- and low-skilled wage formations, as is crucial to the distributional incidence of green taxes. This distinction reveals a new channel in which environmental taxes might be progressive. It acts through wage formation and the differential sensitivity of employment of the two types of labour.

Second, labour tax progressivity acts on the trade-off between efficiency and equity of the reform, such that it increases disincentives to work but also may lower unemployment among low-skilled workers. To establish this contribution, we borrow from literature on labour market performance with progressive tax; for example, a typical argument in public finance indicates that tax progressivity may be detrimental to incentives to work (i.e., labour supply) and lead to an inevitable trade-off between equality and efficiency (Røed and Strøm, 2002; Diamond and Saez, 2011). Yet literature on non-competitive labour markets argues that a more progressive tax schedule remains beneficial for employment (Pissarides, 1998; Sørensen, 1999; Strand, 2002; Hungerbühler et al., 2006; Koskela and Schöb, 2009; Lehmann et al., 2016; Piketty et al., 2014; and Cahuc et al., 2017). Lehmann et al. (2016), in a search and matching framework, show that progressive taxes may contribute to the more efficient allocation of the total tax burden, if the labour demand or extensive margin of low-skilled labour is more sensitive to taxation than that of high-skilled workers. The literature suggests that the extensive margin elasticity is empirically higher for low-skilled workers (e.g., Røed and Strøm, 2002; and Heckman, 1993). And the idea that low-paid employment is more responsive than high-paid employment is common in prior literature (Kramarz and Philippon, 2001; Immervoll et al., 2007). Our study combines low-skilled unemployment and a discrete labour supply, with an intensive supply of high-skilled workers (e.g., Keuschnigg and Ribi, 2009; Saez, 2002), ${ }^{7}$ so we can show that despite possibly high labour supply elasticities, it may be possible to obtain progressivity without lump-sum transfers and accordingly preserve the double dividend.

Third, the existence of a subsistence level of consumption of polluting goods is not neutral in relation

\footnotetext{
${ }^{7}$ Saez (2002) has shown that the relative strength of the intensive and extensive responses is important in the design of optimal tax transfers schedules. If the extensive margin dominates at the low end of the income distribution, it can rationalize an earned income tax credit or wage subsidy.
} 
to the outcome of green tax reforms. In addition to its distributive impacts for the green tax burden, it complicates the trade-off between the first and the second dividends, by reducing the substitutability between clean and dirty goods. This compromises the first dividend but favours the second one, because the tax shift may be larger (Ramsey rule). It also increases social demand for unemployment benefit. Consequently, a decrease of the labour tax rate, that contributes to lower unemployment, will be more beneficial.

The remainder of the paper is organized as follows. We present our model in Section 2. Then in Section 3, we establish the conditions for the regressivity of an uncompensated green tax, using comparative statics. In Section 4, we study and discuss two types of revenue-neutral environmental tax reforms. Section 5 contains some numerical illustrations for France and a sensitivity analysis. Section 6 concludes.

\section{The Model}

In our proposed model, we assume a small open economy composed of firms, the government, and two different types of households that differ in their labour skills. There are a mass $N_{L}=1$ of low-skilled households (indexed with $i=L$ ) and a mass $N_{H}=N$ of high-skilled households $(i=H)$. We consider three types of commodities produced using the same technology: a polluting consumption commodity or "dirty" good $(D)$, that harms the environment when consumed, a "clean" consumption commodity $C$, and a fixed amount of clean public goods $G$. Their prices (before taxes) are fixed and normalized to unity, because we assume the rate of transformation is constant. ${ }^{8}$ Labour is assumed to be immobile internationally, so wages are the only prices determined endogenously in the economy. We further assume structural unemployment in equilibrium caused by hiring costs, and we use a search and matching model to formulate frictions in the labour market with individual worker-firm bargaining. To simplify the analysis, we adopt a static framework. ${ }^{9}$ The government finances public goods $G$, provides fixed unemployment benefit $B$ to unemployed workers, and imposes a tax $t_{i}$ on the labour income of households of type $i$. Moreover, the government imposes a green tax $t_{D}$ on the consumption of the dirty good.

\subsection{Households behaviour}

To model households, we make three assumptions inspired by stylized facts: (1) low-skilled workers supply one unit of labour, whereas the high-skilled labour supply is endogenous (Røed and Strøm, 2002); (2) the risk of unemployment falls on low-wage workers only (e.g., Keuschnigg and Ribi, 2016; Koskela and

\footnotetext{
${ }^{8}$ As Bovenberg and de Mooij (1994) observe, an alternative explanation of the fixed producer prices is possible: Some commodities (e.g., the clean consumption commodity and the public consumption good) can be produced domestically but others (e.g., the dirty goods such as fossil fuels) are imported at exogenous world-market prices.

${ }^{9}$ Diamond (1982) shows that a static model still captures the key mechanisms of the dynamic version of the matching model and can describe "the essence of job search and recruiting externalities".
} 
Schöb, 2009); and (3) there is a subsistence level of consumption for the dirty good (like in Klenert and Mattauch, 2016 and Jacobs and van der Ploeg, 2019).

Assumptions (1) and (2) imply that only low-skilled workers face unemployment, while only skilledones can choose their working hours. We use a search and match model to introduce unemployment for low-skilled households. We justify these choices with the following arguments.

First, recent works argue that frictions in the low-skilled labour market are likely to be greater than in the high-skilled ones (Dolado et al., 2008; Brückner and Pappa, 2012). While low-skilled workers are only able to undertake simple tasks, high-skilled workers can undertake both complex and simple tasks. Then, high-skilled workers may look for better jobs when they land in simple jobs. In turn, simple jobs become more unstable and most costly for firms to open (Dolado et al., 2018). Furthermore, high-skilled workers are likely to have larger networks helping them to find jobs when unemployed, leading to more efficient search intensity. It results in larger frictions for low-skilled workers. Their steady-state vacancy filling and hiring probabilities are lower than that of high-skilled ones. This is in line with the European unemployment rates observations: Low-skilled workers face higher unemployment rates than high-skilled workers do. The skilled mismatch has more a transitory nature leading to job-to-job transitions and is less costly in terms of search in the literature (Dolado et al., 2008). For simplicity, in our model we abstract for high-skilled unemployment.

Second, Pissarides (1998) shows that search and union models are both relevant to describe unemployment in Europe. Both models react in a similar way to a change in the rate or structure of labour taxes. ${ }^{10}$ But the search and match model generates lower employment effects. So, it places us in unfavourable conditions to a double dividend, which strengthens our results. ${ }^{11}$

\subsubsection{Consumption preferences}

Although households differ in their income and leisure time (corresponding to skill levels and labour market activity), we assume they are identical in their consumption tastes. Agents are all risk neutral ${ }^{12}$ and leisure is weakly separable from consumption utility. ${ }^{13}$ Thus we can solve the model analytically.

We assume clean goods and dirty goods are imperfect substitutes in a composite commodity of quantity $Q=q(C, D)$. In contrast to prior literature, we do not allow $q(C, D)$ to be linearly homogeneous

\footnotetext{
${ }^{10}$ In contrast, efficiency wages models are irrelevant as soon as we introduce progressive tax schedule (Pissarides, 1998).

${ }^{11}$ Furthemore, in simple union bargaining model, utilities for employed and unemployed workers are identical (BayındırUpmann and Raith, 2003; Koskela and Schöb; 1999). Their wages are different but their utilities are identical due to disutility of work. This leads to a bias when we deal with efficiency and inequality. There is no incentive to reduce unemployment in regard with inequalities. This is not the case in our model. The static search and match model integrates difference between utilities, without adding complexity compared to union bargaining model.

${ }^{12}$ The indirect utility function depends positively and linearly on income. This assumption places us in the worst case for introducing progressivity of labour income taxes.

${ }^{13}$ If dirty consumption is associated with energy consumption, separability is very likely to hold (Bovenberg and de Mooij, 1994).
} 
in $C$ and $D$. Usual quasi-linear and homothetic preferences imply that the elasticity of substitution between clean and dirty goods is constant and independent of individual skill abilities. It results in constant expenditure shares for polluting goods. However, poor people seem to devote a larger share of their income to the polluting goods consumption than do rich households (e.g., Ruiz and Trannoy, 2008; Metcalf, 1999). An increase in environmental taxes therefore tends to be more harmful for the poor than for the rich. To highlight the relationship between the redistribution and efficiency of green tax reforms, we follow Klenert and Mattauch (2016) and Jacobs and van der Ploeg (2019) and assume Stone-Geary preferences captured by the following consumption utility function $Q_{i}$ :

$$
Q_{i}=q\left(C_{i}, D_{i}\right)=\left(C_{i}\right)^{1-\sigma}\left(D_{i}-\bar{D}\right)^{\sigma},
$$

where $\bar{D}$ denotes the subsistence level for the dirty good, which is the same for all households. The Stone-Geary utility function makes it possible to model a share of consumption that is independent of price changes $(\bar{D})$ and another share that responds instantaneously to price variations $\left(D_{i}-\bar{D}\right)$. With this specification, we can represent dirty goods as necessities (their income elasticity is less than unity). Moreover, the elasticity of substitution between clean and dirty goods increases with income. This reflects the fact that the least able and poorest members of society are hurt most by a green tax (e.g., Deaton et al., 1980; Chung, 1994).

Because the environmental degradation acts as an externality, we assume that households ignore the adverse effect of their demand for polluting goods on the quality of the environment. Consequently, households $i$ choose $C_{i}$ and $D_{i}$ to maximize their utility, subject to their budget constraint: $C_{i}+\left(1+t_{D}\right) D_{i}=I_{i}$ (where $I_{i}$ denotes the income of households $i$ ). From the first-order conditions of the maximization of Equation (1), we obtain the uncompensated demands for goods $D$ and $C$, as well as the indirect utility of consumption:

$$
D_{i}^{*}=\frac{\sigma}{1+t_{D}}\left[I_{i}-\left(1+t_{D}\right) \bar{D}\right]+\bar{D} ; \quad C=(1-\sigma)\left[I_{i}-\left(1+t_{D}\right) \bar{D}\right] ; \quad Q_{i}^{*}=\frac{\left[I_{i}-\left(1+t_{D}\right) \bar{D}\right]}{P_{Q}}
$$

where $P_{Q}=\left[\frac{1}{1-\sigma}\right]^{1-\sigma}\left[\frac{\left(1+t_{D}\right)}{\sigma}\right]^{\sigma}$ can be interpreted as the marginal price of consumption, independent of individual abilities. ${ }^{14}$ Consumers first purchase a subsistence level of the polluting good that costs $\left(1+t_{D}\right) \bar{D}$. Then, they decide how to allocate their leftover income $\left(I_{i}-\left(1+t_{D}\right) \bar{D}\right)$ between polluting and non-polluting goods, according to their respective preference parameter $(\sigma, 1-\sigma)$, similar to classical Cobb-Douglas preferences. The assumption of households' risk neutrality implies that their indirect

\footnotetext{
${ }^{14}$ Although $P_{Q}$ is equal to the inverse of the private marginal utility of income (i.e. the Lagrange multiplier associated with the budget constraint of the household), $P_{Q}$ does not correspond to the implicit price of aggregated consumption. Because the Stone-Geary utility function is non-homogeneous, the price index $P_{i}$ depends on income and varies across individuals $\left(P_{i} Q_{i}^{*}=I_{i}=>P_{i}=\left(\frac{I_{i}}{I_{i}-\left(1+t_{D}\right) \bar{D}}\right) P_{Q}\right)$. The marginal price of consumption $P_{Q}$ is still constant, because we require incomes to be high enough to purchase a subsistence level of the polluting good $\left(I_{i}>\left(1+t_{D}\right) \bar{D}\right)$.
} 
consumption utility $\left(Q_{i}^{*}\right)$ reflects the purchasing power of their leftover income.

\subsubsection{Income and welfare}

For low-skilled workers, we use a static matching framework, so the ex ante probability of being unemployed $u$, is equal to the ex post unemployment rate. ${ }^{15}$ The indirect utility of low-skilled workers, denoted $V_{L}$, is then defined as: $V_{L}=u * V_{L}^{U}+(1-u) * V_{L}^{E}$; where $V_{L}^{U}$ and $V_{L}^{E}$ denote the indirect utility of unemployed and employed low-skilled workers respectively (hereafter, we mark relevant variables for the low-skilled workers with the subscript $E$ or $U$, depending on whether they are employed or unemployed). ${ }^{16}$ Low-skilled workers supply one unit of labour at wage $w_{L}\left(1-t_{L}\right)$, net of tax, if they are employed. If unemployed, they receive a unemployment benefit $B$, given by some fixed nominal payment, ${ }^{17}$ and enjoy a utility of leisure $Z$ (Pissarides, 2000). We also assume that environmental externality enters the utility function linearly, so that our equation can be rewritten as:

$$
V_{L}=u *\left[Q^{*}(B)+Z\right]+(1-u) * Q^{*}\left(w_{L}\left(1-t_{L}\right)\right)-\psi\left[D_{t o t}\right],
$$

where $-\psi\left[D_{t o t}\right]$ denotes the dis-utility due to the environmental degradation caused by the aggregated consumption of the polluting good, $D_{t o t}=D_{L}+N D_{H}$.

In contrast, given an hourly wage net of $\operatorname{tax} w_{H}\left(1-t_{H}\right)$, skilled workers supply variable labour $H$. High-skilled workers' welfare $V_{H}$ is an increasing linear function of income $I_{H}$ minus a given convex increasing effort cost $\varphi(H)$ and the disutility due to the environmental degradation:

$$
V_{H}=\left(\max _{H}\left[Q^{*}\left(I_{H}\right)-\varphi(H)\right]\right)-\psi\left[D_{t o t}\right] \quad \text { s.t. } I_{H}=w_{H}\left(1-t_{H}\right) * H
$$

If the effort cost function takes the form $\frac{H^{1+\frac{1}{\eta_{H}}}}{1+\frac{1}{\eta_{H}}}$ (where $\eta_{H}$ reflects the Frish elasticity of labour supply to wage), we get a skilled labour supply of

$$
H^{*}=\left(\frac{w_{H}\left(1-t_{H}\right)}{P_{Q}}\right)^{\eta_{H}}
$$

\footnotetext{
${ }^{15}$ See Diamond (1982), Snower (1996), Sato (2004), Hungerbühler et al. (2006), and Keuschnigg and Ribi (2009) for examples of static search and matching models.

${ }^{16}$ Following Merz (1995), we avoid distributional issues from heterogeneity among low-skilled households, by thinking each household as a very large extended family which contains a continuum of members, pools income and then redistributes it equally to all members. But because agents are risk-neutral in our model, we could ignore the absence of implicit or explicit income insurance (Diamond, 1982).

${ }^{17}$ Indexation of unemployment benefits under a green tax reform is discussed by Koskela and Schöb (1999).
} 


\subsection{Firms' behavior}

\subsubsection{Technology}

There is only one production sector that indifferently produces the dirty good or clean goods, including public ones. Because all goods are produced at constant and identical unit costs, we can normalize production prices to unity. We assume a mass 1 of firms that produce output $y$ with labour as the only variable input. Following Keuschnigg and Ribi (2009), the technology is homothetic and displays constant returns to scale. ${ }^{18}$ The firm acquires labour services by high-skilled workers $(h=N H)$ and low-skilled workers $(l=L)$ to produce the raw value added:

$$
y=f(l, h)=l^{\alpha} h^{1-\alpha} \quad \text { with } \quad 0<\alpha<1
$$

where $f$ is a homogeneous Cobb-Douglas function. Defining $p_{i}$ as the total cost per unit of labour i (i.e., labour productivity), a profit maximization $\pi(y)=\max _{l, h}\left[y-\left(l p_{L}+h p_{H}\right)\right]$ s.t. $y=f(l, h)$ gives $p_{L} l=\alpha y$ and $p_{H} h=(1-\alpha) y$. The Cobb-Douglas technology implies constant cost shares.

As mentioned, we use a static version of a simple search and matching model of the labour market to model unemployment among low-skilled workers. Implicit heterogeneities (or mismatches), capture informational frictions in the labour market. They are assumed to lead to a transaction cost that makes it costly for a low-skilled worker or firm to find a partner. A matching function summarizes these labour market heterogeneities and the formation rate of matches (Pissarides, 1998). For a mass 1 of job searchers and number of vacant jobs $v$, the matching function is defined as $\mathcal{M}(v, 1)$, with positive first partial derivatives, negative second derivatives, and constant returns to scale. The matching function implies that a firm looking for a low-skilled worker finds one with a probability of less than 1, equal to $\frac{\mathcal{M}}{v}$, even if there are enough jobs to satisfy all workers. Denoting $\theta=\frac{v}{1}$ as the tightness ratio of the labour market, we rewrite this probability as $q(\theta)=\frac{\mathcal{M}}{v}=\mathcal{M}(1,1 / \theta)$. It represents a Poisson matching probability of a vacant job, that is, the rate at which vacant jobs get filled. Symmetrically, the rate at which an unemployed worker finds a job is $\theta q(\theta)=l=\mathcal{M}$. Among low-skilled workers, $\theta q(\theta)$ are employed and $[1-\theta q(\theta)]$ are unemployed. ${ }^{19}$ The standard Beveridge curve is:

$$
u=[1-\theta q(\theta)]=1-l .
$$

\footnotetext{
${ }^{18}$ The firm production function shows diminishing marginal productivity for each type of skill. In this context, the firm is incited to employ more low-skilled workers in order to reduce wages, which induces a bias and leads to overemployment. For discussions, see Stole and Zwiebel (1996) and Cahuc et al. (2008).

${ }^{19} \mathrm{As}$ in all static versions of the model, there is no exogenous quitting. At the initial time, there is one representative firm with $v$ empty vacancies that need to be filled, along with a mass 1 of low-skilled households willing to work. The matching function means that at the end, $\theta q(\theta)$ workers get a job, and $q(\theta) v$ vacancies are filled. Everything is expressed as if there is only one representative low-skilled household that faces a probability $(1-\theta q(\theta))$ of being unemployed.
} 
Firms must post their vacancy to hire low-skilled workers. Maintaining a vacancy would cost them $c$ units of output, which constitutes a fixed cost of low-skilled labour recruitment, measured in terms of the numeraire good (Pissarides, 2000). Before paying the cost of posting, a firm is not sure it will match with a worker. Due to frictions, a vacant job $v$ is matched to an unemployed worker with probability $q(\theta)<1 .{ }^{20}$ If the vacancy is finally occupied (rate $q(\theta)$ ), firms pay workers a wage $w_{L}$. Given these elements, firms maximize their expected profit $\pi=\max _{h, v}\left(y-w_{H} h-w_{L} l-c v\right)$; subject to $l=v * q(\theta)$ and $y=f(l, h)$. First-order conditions give the traditional job creation and labour demand equations:

$$
\begin{gathered}
\left(\frac{\partial f}{\partial l}-w_{L}\right) q(\theta)=c \quad \Leftrightarrow \quad \frac{\partial f}{\partial l}=p_{L} \quad(7.1) \quad \text { and } p_{L}=w_{L}+\frac{c}{q(\theta)}, \\
\text { and } \quad \frac{\partial f}{\partial h}=p_{H}=w_{H} .
\end{gathered}
$$

The high-skilled labour market is competitive. Consequently, firms hire high-skilled labour until marginal productivity is equal to the wage (8). The total cost of low-skilled workers per unity of labour $\left(p_{L}\right)$ exceeds the wage by recruitment's costs $\left(\frac{c}{q(\theta)}\right)$ (Equation 7.2). Equation (7) represents a traditional "job creation condition" in that the marginal cost of investing in a job vacancy (c) equals the expected job rent $\left(\left(\frac{\partial f}{\partial l}-w_{L}\right) * q(\theta)\right)$. In fine, the expected profit is zero in this model due to our assumption of constant returns to scale.

\subsubsection{Low-skilled wage determination}

Once a suitable low-skilled worker is found, a job rent appears that corresponds to the sum of the expected search and hiring costs for the firm and the worker. The wage needs to share this economic (localmonopoly) rent, in addition to compensating both parties for the assets accrued from forming the job. We assume a decentralized Nash bargain, which imposes a particular splitting of the matching surplus between the two parties involved, according to their relative bargaining power (Pissarides, 2000). For a low-skilled worker, the matching surplus is the difference between the expected utility when employed and that when unemployed: $Q^{*}\left(w_{L}\left(1-t_{L}\right)\right)-\left(Q^{*}(B)+Z\right)$. For a firm, the matching surplus is the difference between the profit when it fills a vacancy and when the firm remains with a vacant job: $\left(p_{L}-w_{L}-c\right)-(-c)=$ $p_{L}-w_{L}$. In turn, the low-skilled wage is $w_{L}=\operatorname{argmax}\left\{\left(Q^{*}\left(I_{L}^{E}\right)-\left(Q^{*}\left(I_{L}^{U}\right)+Z\right)\right)^{\beta}\left(p_{L}-w_{L}\right)^{1-\beta}\right\}$ with $\beta \in] 0 ; 1[$ indicating the low-skilled worker's bargaining power. Appendix A shows that the firstorder condition for the maximization of the Nash product implies the following expression of the wage

\footnotetext{
${ }^{20}$ As in Pissarides (1998) and Keuschnigg and Ribi (2009), we assume for simplicity "one shot matching so that no other search opportunity is available".
} 
mark-up, denoted $M$ :

$$
M=\frac{P_{Q}\left(Q^{*}\left(I_{L}^{E}\right)-Q^{*}\left(I_{L}^{U}\right)-Z\right)}{\left(1-t_{L}\right)}=\frac{\beta}{1-\beta} *\left(\frac{c}{q(\theta)}\right)=\frac{\beta}{1-\beta}\left(p_{L}-w_{L}\right),
$$

where $M$ is defined as the difference between the wage $w_{L}$ and the reservation wage $w_{R}$, for which a household is indifferent between being employed or unemployed. If hiring costs are zero $(c=0)$, in equilibrium, $M=0$. Thus, positive hiring costs increase the gap between the utility of employment and that of unemployment. Similarly, a drop in job vacancies (or $\theta$ ) decreases the expected value of the firm's hiring $\operatorname{costs}\left(\frac{c}{q(\theta)}\right)$, which reduces the rents from the job match and decreases the wage mark-up too. Because $w_{R}=\frac{B+P_{Q} Z}{1-t_{L}}$ in this model, another formulation of Equation (9) (see Appendix A) thus can be given by:

$$
w_{L}=w_{R}+\beta\left(p_{L}-w_{R}\right)
$$

That is, workers receive their reservation wage $w_{R}$ and a fraction $\beta$ (reflecting their bargaining power) of the net surplus that they create by accepting the job (Pissarides, 2000). If the bargaining power of the low-skilled worker tends toward $1(\beta \rightarrow 1)$, the low-skilled wage equals the productivity of lowskilled labour (similar to a competitive labour market). Labour demand does not depend on hiring costs $\left(\frac{c}{q(\theta)}=0\right)$. Instead, if the firm alone has bargaining power $(\beta \rightarrow 0)$, the wage just equals the reservation wage.

\subsection{Government budget constraint}

To finance unemployment benefits $B$ and public goods $G$, the government levies a tax $t_{i}$ on wages $i$ and a green tax $t_{D}$ on the consumption of the dirty good $D$. The burden of the labour income tax depends on the nominal wage rate $w_{i}$, and the income tax rate $t_{i}$, which is assumed to be progressive: $t_{H} \geqslant t_{L}$. The government budget constraint can then be written as:

$$
G+(1-l) B=l w_{L} t_{L}+N H w_{H} t_{H}+t_{D} D_{t o t}
$$

\section{Uncompensated Green Tax: Comparative Statics}

In this section, we analyse the impact of an exogenous infinitesimal increase of green taxes on employment, welfare, and inequalities. We do not impose the constraint that the government must balance its spending with its revenues yet (this assumption is relaxed in Section 4). We treat the additional revenue raised by the increase of green/labour taxes as savings and thus do not take the government budget constraint from Equation (11) into account. Accordingly, we define the partial equilibrium of the model as a tuple $\left(l^{*}, H^{*}, \theta^{*}, w_{L}^{*}, w_{H}^{*}, \frac{\partial f^{*}}{\partial l}, y^{*}\right)$ that satisfies the job creation condition from Equation (7.2), the wage mark- 
up Equation (10), the Beveridge curve in Equation (6), the high-skilled labour supply from Equation (4), firms' labour demands in Equations (7.1) and (8), and the production function from Equation (5). Due to the properties of the matching function and our assumption regarding the non-perfect substitutability of labour, it is not possible to solve explicitly the equilibrium in levels. We instead examine the local behaviour of this economy around the initial equilibrium: The model is log-linearized. We use a tilde $(\sim)$ to denote percentage relative changes to initial values (i.e., $\tilde{l}=\frac{d l}{l}$ ), except for the tax rate changes defined as $\tilde{t_{D}}=\frac{d t_{D}}{1+t_{D}}, \tilde{t_{L}}=\frac{d t_{L}}{1-t_{L}}$, and $\tilde{t_{H}}=\frac{d t_{H}}{1-t_{H}}$. Table B.1 in Appendix B summarizes the log-linearized form of the partial equilibrium equations.

\subsection{Partial equilibrium: Revenue and employment effects}

\subsubsection{High-skilled labour market}

In the perfect high-skilled labour market, high-skilled productivity is equal to wages $\left(p_{H}=w_{H}\right)$, and moves to equalize labour demand (Equation (8)) and labour supply (Equation (4)). Log-linearizing these two equations gives us:

$$
\tilde{h}^{d}=\tilde{y}-\widetilde{p_{H}} \quad(\tilde{8}) ; \quad \tilde{h}^{s}=\eta_{H}\left(\widetilde{p_{H}}-\left(\sigma \tilde{t_{D}}+\tilde{t_{H}}\right)\right)
$$

The high skilled labour demand (Equation $\tilde{8}$ ) increases with production and decreases with the cost of labour (i.e., wage). On the other side, labour supply is an increasing function of the real after-tax wage $\left(\frac{w_{H}\left(1-t_{H}\right)}{P_{Q}}\right)$. High-skilled workers are more willing to supply labour when their wages are higher, and when the marginal price of consumption $\left(P_{Q}\right)$ and labour taxes are lower. In Equation $(\tilde{4})$, increasing green taxes contributes to increase the marginal price of consumption $\left(\widetilde{P_{Q}}=\sigma \tilde{t_{D}}\right)$, which discourages high-skilled workers from supplying their labour. Increasing green taxes thus leads to a decrease of labour

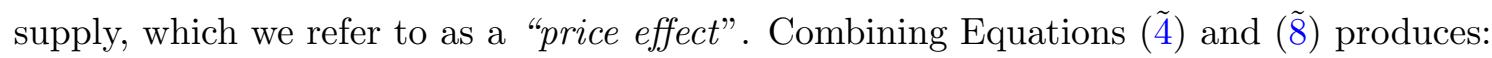

$$
\widetilde{h}^{*}=\frac{\eta_{H}}{\left(1+\eta_{H}\right)} \tilde{y}^{*}-\frac{\eta_{H}}{\left(1+\eta_{H}\right)}\left(\sigma \tilde{t_{D}}+\tilde{t_{H}}\right)
$$

\subsubsection{Low-skilled labour market}

In the low-skilled labour market, labour demand is similar to that for the high-skilled market, and given by:

$$
\widetilde{l}^{d}=\tilde{y}-\widetilde{p_{L}}
$$

However, due to frictions, productivity (i.e., marginal cost of labour) differs, according to recruitment costs (Equation 7.2). The labour market is imperfect and its "supply side" entails the level of employment determined by three equations: Beveridge curve (6), job creation (7.2), and the wage bargaining solution 
(10). Log-linearization of the matching function and the Beveridge curve in Equation (6) implies:

$$
\tilde{l}=(1-\xi) * \tilde{\theta}
$$

where $0<\xi=-\frac{\partial q(\theta)}{q(\theta)} * \frac{\theta}{\partial \theta}<1$. The tightness $(\theta)$ is equal to ratio of job searchers on vacancies. Thus, a raise in $\theta$ increases the probability that low-skilled workers find a job and reduces the rate $q(\theta)$ that a firm fills vacancies (Keuschnigg and Ribi, 2009). Employment (l) rises with labour market tightness, but the unemployment rate $(u=1-l)$ falls. ${ }^{21}$ Log-linearizing the job creation condition (7.2) gives:

$$
\tilde{p_{L}}=\frac{w_{L}}{p_{L}} * \tilde{w_{L}}+\frac{c}{q(\theta)} \frac{\xi}{p_{L}} * \widetilde{\theta}
$$

An increase in labour market tightness reduces the probability $q(\theta)$ that a firm finds a worker and raises the cost of filling a vacancy $\frac{c}{q(\theta)}$, which in turn increases the marginal cost of low-skilled labour (i.e., productivity), as well as wages. Log-linearizing the bargaining condition from Equation (10), we obtain a wage response:

$$
\widetilde{w_{L}}=\beta \frac{p_{L}}{w_{L}} \tilde{p_{L}}+(1-\beta) \frac{w_{R}}{w_{L}}\left(\tilde{w_{R}}\right) .
$$

Due to the strictly positive job surplus allowed by the workers' bargaining power, any increase in the reservation wage or productivity $p_{L}$ inflates gross wages. ${ }^{22}$ Noting that $\tilde{w_{R}}=\tilde{t_{L}}+\sigma \frac{P_{Q} Z}{B+P_{Q} Z} \tilde{t_{D}}$, and combining Equations (7.2), ( $\tilde{6})$ and (10), we express the employment change as a function of low-skilled workers' productivity change:

$$
\tilde{l}=\eta_{L} \widetilde{p_{L}}-\eta_{R}\left(\tilde{t_{L}}+\sigma \frac{P_{Q} Z}{B+P_{Q} Z} \tilde{t_{D}}\right)
$$

where $\eta_{L}=\frac{1-\xi}{\xi}\left[\frac{p_{L}}{p_{L}-w_{R}}\right]$, and $\eta_{R}=\eta_{L} \frac{w_{R}}{p_{L}}$, to reflect the elasticities of low-skilled employment with respect to the change of productivity and outside option. The last term of Equation (13), $\left(\tilde{t_{L}}+\sigma \frac{P_{Q} Z}{B+P_{Q} Z} \tilde{t_{D}}\right)$, indicates variation in the reservation wage $\left(\tilde{w_{R}}\right)$ with tax variations $\tilde{t_{L}}$ and $\tilde{t_{D}}$. Increasing the rate of one of these two taxes makes the outside option $\left(w_{R}\right)$ more attractive for unemployed workers. Although obvious for the labour tax rate, the impact of environmental taxes on the reservation wage is indirect, through the marginal price of consumption: $P_{Q}$ becomes higher, which increases the utility of leisure in monetary terms $\left(P_{Q} * Z\right)$, as well as the reservation wage $\left(w_{R}=\frac{B+P_{Q} Z}{1-t_{L}}\right) .{ }^{23}$ Any increase of the outside

\footnotetext{
${ }^{21}$ For a fixed level of productivity (e.g., perfect substitutability of labour), the job creation condition is a downward-sloping curve in $\left(w_{L}, \theta\right)$. The inverse relationship between wage costs and labour market tightness can be explained as follows: An increase in wage costs reduces the expected benefits of an occupied job. Market tightness is such that the expected profit of a new job equals expected hiring costs. To re-establish arbitrage between the costs and benefits of hiring new workers, labour market tightness must decrease in response to an increase in wages (Pissarides, 2000).

${ }^{22}$ As noted by Keuschnigg and Ribi (2009), tax shifting weakens when benefits are indexed to net wages. Some tax shifting occurs as long as the indexation of benefits is not complete.

${ }^{23}$ If $\mathrm{Z}=0$, green taxes have no direct impact on the low-skilled market.
} 
option pushes workers to claim a higher wage. The wage curve from Equation (10) shifts upward. The low-skilled labour market becomes less tight, firms create fewer jobs (downshift in the job creation curve from Equation (7.2)) and unemployment increases. Thus, in the low-skilled market, the uncompensated increase of environmental taxes leads to a "price effect", that lowers unemployment. Combining Equations (7.1) and (13), we get:

$$
\tilde{l}=\frac{\eta_{L}}{\left(1+\eta_{L}\right)} \tilde{y}-\frac{\eta_{R}}{\left(1+\eta_{L}\right)}\left(\tilde{t_{L}}+\sigma \frac{P_{Q} Z}{B+P_{Q} Z} \tilde{t_{D}}\right)
$$

\subsubsection{Partial equilibrium: Interaction between labour markets}

Due to our assumption of non-perfect substitution of labour, the two labour markets interact. By replacing $\tilde{y}=\alpha \widetilde{l}+(1-\alpha) \tilde{h}$ and using Equations $(\tilde{8})$ and $(\tilde{7})$, we obtain: $\widetilde{p_{H}}=-\frac{\alpha}{1-\alpha} \widetilde{p_{L}}$. Skilled and unskilled labour can be substituted, depending on the change in relative prices, or the ratio of labour productivities $\left(\tilde{l}-\tilde{h}=\widetilde{p_{H}}-\widetilde{p_{L}}\right)$. If the high-skilled labour supply and outside option reactions to taxes are exactly the same, productivities would remain unchanged $\left(\widetilde{p_{L}}=\widetilde{p_{H}}=0\right)$, and labour would decrease at the same proportion for high- and low-skilled workers $(\tilde{l}=\widetilde{h}=\widetilde{y})$. Otherwise, firms have the option to substitute inputs, which affects labour productivities, and then labour and wages. Using Equations (14) and (12), to eliminate $\tilde{y}$, as well as $\tilde{l}-\tilde{h}=\widetilde{p_{H}}-\widetilde{p_{L}}=-\frac{1}{1-\alpha} \widetilde{p_{L}}$, we can find the low-skilled productivity change:

$$
{\widetilde{p_{L}}}^{*}=\frac{(1-\alpha)}{1+(1-\alpha) \eta_{L}+\alpha \eta_{H}}\left[\eta_{R}\left(\tilde{t_{L}}+\sigma \frac{P_{Q} Z}{B+P_{Q} Z} \tilde{t_{D}}\right)-\eta_{H}\left(\sigma \tilde{t_{D}}+\tilde{t_{H}}\right)\right] .
$$

If the labour supply of high-skilled workers is less elastic to environmental taxes than the low-skilled sensitivity of the outside option is $\left(\eta_{H} \sigma \tilde{t_{D}}<\eta_{R} \sigma \frac{P_{Q} Z}{\overline{B+P_{Q} Z}} \tilde{t_{D}}\right)$, an increase of the green tax rate decreases the high-skilled labour supply incentive relatively less than the low-skilled workers' participation. Firms need to increase low-skilled wages relatively more in order to attract them. Consequently, the ratio of high-skilled to low-skilled productivities decreases, and production becomes more high-skilled labour intensive. Increasing green taxes leads to a substitution between low- and high-skilled labour and has an ambiguous effect on productivities. We refer to it as a substitution effect.

We thus identify two main effects of a raise in uncompensated green taxes: (i) a price effect, as a higher green tax raises the marginal price of consumption $\left(P_{Q}\right)$, and decreases the outside option of low-skilled workers and the leisure's utility of high-skilled ones, that contributes in lowering low-skilled employment, and high-skilled labour supply; and (ii) a substitution effect, as a higher green tax incites firms to substitute between low and high-skilled labour depending, on the difference between high-skilled labour supply and outside option reactions to green taxes. The substitution effect has ambiguous impacts on productivities, wages and the ratio of low- and high-skilled labour. The full log-linearized solutions of the system are in Table B.2 in Appendix B. We find an unambiguous negative effect of green taxes on low-skilled employment and high-skilled labour (the price effect overcomes the substitution effect). The 
impact on productivities is still undetermined. Proposition 1 summarizes these arguments (see the proof in Appendix C).

Proposition 1. If the utilities of low- and high-skilled workers do not depend on leisure, a higher uncompensated green tax leaves employment and productivities unaffected. Otherwise, a higher uncompensated green tax: (i) decreases high-skilled labour, low-skilled employment, and production; (ii) has an ambiguous impact on the ratios of productivities and of both types of labour. The lower the elasticity of the high-skilled labour supply with respect to green taxes, compared with low-skilled labour sensitivity to the outside option $\left(\eta_{H}<\eta_{R} \frac{P_{Q} Z}{B+P_{Q} Z}\right)$, the higher the ratio of low-skilled to high-skilled productivities is (i.e., the production becomes more high-skilled labour intensive).

\subsection{Welfare analysis}

We measure the welfare effects of small tax changes with the marginal excess burden, which corresponds to the additional income that needs to be provided to the representative household in each category, to keep its utility at its initial level. This compensatory income variation, denoted $d R$, stands for the excess welfare loss of consumers over and above the tax revenues collected by the government, and it can be interpreted as the hidden costs of financing public spending: A positive value for the marginal excess burden indicates a loss in welfare after the tax reform. We seek to determine the compensatory income variation that, after tax reform, would leave welfare unchanged $\left(d V_{H}, d V_{L}=0\right)$. For high-skilled workers, we obtain:

$$
d V_{H}=0 \Leftrightarrow \frac{\partial V_{H}}{\partial C_{H}} d C_{H}+\frac{\partial V_{H}}{\partial D_{H}} d D_{H}+\frac{\partial V_{H}}{\partial H} d H+\frac{\partial V_{H}}{\partial D_{t o t}} d D_{t o t}=0 .
$$

Using first-order conditions of the consumer's program, it leads to:

$$
d V_{H}=0 \Leftrightarrow \frac{d C_{H}}{P_{Q}}+\frac{\left(1+t_{D}\right)}{P_{Q}} d D_{H}+\frac{w_{H}\left(1-t_{H}\right)}{P_{Q}} d H+\frac{\partial V_{H}}{\partial D_{t o t}} d D_{t o t}=0 .
$$

By differentiating the budget constraint of high-skilled households and using the definition of the compensatory income variation we obtain:

$$
d C_{H}+\left(1+t_{D}\right) d D_{H}+D_{H} d t_{D}=\left(1-t_{H}\right) w_{H} d H+H\left(1-t_{H}\right) d w_{H}-H w_{H} d t_{H}+d R_{H} .
$$

Combining the last two equations, we obtain:

$$
d R_{H}=\underbrace{-[\underbrace{I_{H}\left(\widetilde{w_{H}}-\tilde{t_{H}}\right)}_{\Delta_{H}^{w}}-\left(1+t_{D}\right) \underbrace{D_{H} \tilde{t_{D}}}_{\Delta_{H}^{D}}]}_{\Delta_{H}^{P P}}-\underbrace{\frac{\partial V_{H}}{\partial D_{t o t}} P_{Q} d D_{t o t}}_{\Delta_{H}^{e}} .
$$


The compensatory income variation is the variation of revenue needed to overcome the deterioration of environmental quality $\Delta_{H}^{e}$ and the purchasing power variation $\left(\Delta_{H}^{P P}\right)$, equal to the sum of the variation of the after-tax wage $\left(\Delta_{H}^{w}\right)$ and the increase of price of the polluting good $\left(\Delta_{H}^{D}\right)$.

In Appendix D we derive the compensatory variation for the low-skilled workers:

$$
d R_{L}=\underbrace{-[l \underbrace{I_{L}^{E}\left(\widetilde{w_{L}}-\tilde{t_{L}}\right)}_{\Delta_{L}^{w}}+\underbrace{P_{Q}\left(V_{L}^{E}-V_{L}^{U}\right) d l}_{\Delta_{L}^{E}}-\underbrace{\left(1+t_{D}\right) D_{L} \tilde{t_{D}}}_{\Delta_{L}^{D}}]}_{\Delta_{L}^{P P}}-\underbrace{\frac{\partial V_{L}}{\partial D_{t o t}} P_{Q} d D_{t o t}}_{\Delta_{L}^{e}},
$$

using similar notations, and $\Delta_{L}^{P P}$ is the purchasing power effect for the low-skilled workers (incorporating $I_{L}^{E}=w_{L}\left(1-t_{L}\right)$, or the revenue of the unskilled worker when employed). Due to imperfections in the labour market of low-skilled workers, we add another term to the compensatory variation of the unskilled worker: an employment effect $\Delta_{L}^{E}$, proportional to the difference between the utility of an employed $\left(V_{L}^{E}\right)$ and unemployed $\left(V_{L}^{U}\right)$ worker. Another formulation of Equation (16) (see in Appendix D), can be given by:

$$
d R_{L}=\underbrace{-[l I_{L}^{E}\left(\left(\frac{\beta}{\xi} \frac{p_{L}}{w_{L}} \widetilde{p_{L}}-\tilde{t_{L}}\right)+\left[\frac{\xi-\beta}{\xi}\right] \frac{w_{R}}{w_{L}} \widetilde{w_{R}}\right)-\underbrace{\left(1+t_{D}\right) D_{L}}_{\Delta_{L}^{D}} \tilde{t_{D}}]}_{\Delta_{L}^{P P}}-\underbrace{\frac{\partial V_{L}}{\partial D_{t o t}} P_{Q} d D_{t o t}}_{\Delta_{L}^{e}} .
$$

This equation gives us an opportunity to interpret the compensatory variation of low-skilled workers according to the Hosios (1990) condition, which defines the "optimality" of the low-skilled employment equilibrium, ${ }^{24}$ according to both congestion externalities (workers do not internalize the notion that if they look for a job, they create new jobs at a lower rate than their own probability of finding a job; this leads to too much unemployment) and appropriability problems (workers only appropriate a fraction of the private value of their jobs; so the value of looking for a job, or the opportunity cost of working, is underestimated, which leads to insufficient job search by workers and too little unemployment). In the Hosios condition, the appropriability and congestion problems in the low-skilled labour market exactly balance each other. With our assumption of constant returns to scale of the matching function, the Hosios condition is satisfied if workers' share of the surplus of a match $(\beta)$ is equal to the elasticity of the matching function $(\xi) .{ }^{25}$ If $\beta>\xi$, there is too much unemployment and the appropriability problem dominates congestion externality on firms' side, or vice versa, on the workers' side. Both effects push

\footnotetext{
${ }^{24}$ We refer to the Hosios condition only in terms of economic efficiency in the low-skilled market. It does not account for environmental externalities.

${ }^{25}$ Without pre-existing labour taxes, the Hosios condition equals the match elasticity to the bargaining parameter. This condition still holds in our context, with a fixed labour supply for low-skilled workers and for fixed unemployed benefits, due to our static framework (see Arseneau and Chugh, 2006).
} 
unemployment above the optimum. If $\xi>\beta$, the unemployment rate is below the optimum. In the case that $\beta=\xi, d R_{L}=-\left(l I_{L}^{E}\left(\frac{p_{L}}{w_{L}} \widetilde{p_{L}}-\tilde{t_{L}}\right)-\left(1+t_{D}\right) D_{L} \tilde{t_{D}}\right)-\frac{\partial V_{L}}{\partial D_{t o t}} P_{Q} d D_{t o t}$. Like for high-skilled labour, the compensatory income variation is driven only by the increase of productivity $p_{L}$, the labour tax rate $t_{L}$, the increase of the price of the polluting good $\Delta_{L}^{D}$, and the deterioration of environmental quality $\Delta_{L}^{e}$. Compensatory income variations of high - and low-skilled labour are really similar in this case.

If $\beta>\xi$, unemployment is higher than the "optimal" level, and increasing the reservation wage (due to higher environmental or labour taxes), pushes wages to increase, creating even more unemployment. The situation deteriorates and increases the compensatory income variation of low-skilled workers. In the opposite case, if $\beta<\xi$, the unemployment rate lies below the optimum, so increasing the reservation wage still would push wages to increase and create more unemployment. Regarding externalities, the labour market would move closer from the optimum and the compensatory income variation of low-skilled labour would decrease. As do Bovenberg and de Mooij (1994), we distinguish an environmental component and a non-environmental one: in Equations (12) and (14), the marginal excess burden is the sum of an effect on the loss of purchasing power $\Delta^{P P}$ and an environmental effect $\Delta^{e}$. We do not allow for heterogeneous valuations of damages from pollution, so the regressivity of environmental taxes only appears through the loss of purchasing power, proportional to the income of the agents. With these specifications, we define regressivity only in terms of purchasing power, abstracting from the environmental component, as specified next.

Definition 1. A green tax is regressive (progressive), if and only if the relative loss of purchasing power caused by an increase of the tax rate is lower (higher) for high-skilled than for low-skilled workers.

$$
\frac{\Delta_{H}^{P P}}{I_{H} d t_{D}}=-[\frac{d w_{H}}{w_{H} d t_{D}}-\underbrace{\frac{D_{H}}{I_{H}}}_{\Delta_{H}^{D}}] \lessgtr \frac{\Delta_{L}^{P P}}{I_{L} d t_{D}}=-[\left(\frac{l I_{L}^{E}}{I_{L}}\left(\frac{\beta}{\xi} \frac{p_{L}}{w_{L}} \frac{d p_{L}}{p_{L} d t_{D}}\right)+\left[\frac{\xi-\beta}{\xi}\right] \frac{w_{R}}{w_{L}} \frac{d w_{R}}{w_{R} d t_{D}}\right)-\underbrace{\frac{D_{L}}{I_{L}}}_{\Delta_{L}^{D}}] .
$$

Proposition 2. If (i) the low-skilled labour market exhibits the Hosios condition ( $\beta=\xi$ ), (ii) preferences for polluting goods are homothetic $(\bar{D}=0)$, and (iii) the substitution between the two types of labour is perfect, any uncompensated increase in the green tax rate leaves the initial distribution unaffected. The relax of one of these assumptions is enough to lead to a distributive impact of green taxes.

The proof follows directly from the definition. With perfect substitution of types of labour, productivities are exogenous, so $\frac{d w_{H}}{w_{H} d t_{D}}=\frac{d p_{L}}{p_{L} d t_{D}}=0$, and under the Hosios condition we would obtain $\frac{\Delta_{i}^{P P}}{I_{i} d t_{D}}=-\frac{D_{i}}{I_{i}}$ for $i=L, H$. The homothety assumption ensures that this ratio is the same for low- and high-skilled workers.

If we relax one of these assumptions, green taxes lead to a distributive impact. The non-homothety of the utility function $(\bar{D}>0)$ acts through the use of households' income, or how they spend their revenue. 
The higher $\bar{D}$, the higher the low-skilled share of dirty goods consumption in their total spending relative to that for the high-skilled households. Thus $\Delta_{L}^{D}>\Delta_{H}^{D}$, which leads to a regressive effect. The Hosios condition and non-perfect substitution of types of labour influence the formation of households' revenue. The revenue effect (or sources side effect) is ambiguous, in that it depends on the level of congestion and appropriability problems (i.e., the ratio of $\frac{\beta}{\xi}$ ) as well as the substitution effect. If $\beta>\xi(\xi>\beta)$ unemployment is higher (lower) than the "optimal" level and any increase of green taxes increases the reservation wage, pushing wages to increase and creating more unemployment, which raises (decreases) the compensatory income variation of low-skilled workers and again favours regressivity. However, if $\eta_{H}>\eta_{R} \frac{P_{Q} Z}{B+P_{Q} Z}$ , the reaction of low-skilled workers to environmental taxes is low, relative to the reaction in the labour supply of high-skilled workers. Firms need to increase high-skilled wages relatively more than low-skilled ones to raise the supply incentive, in favor of regressivity. Table 1 details conditions in which the revenue effect can be progressive or regressive; Proposition 3 summarizes the previous arguments.

Table 1: Distributive impacts of uncompensated green taxes on the revenue formation

\begin{tabular}{llll} 
& $\beta<\xi$ & $\beta=\xi$ & $\beta>\xi$ \\
\hline$\eta_{H}<\eta_{R} \frac{P_{Q} Z}{B+P_{Q} Z}$ & progressive & progressive & ambiguous* \\
$\eta_{H}=\eta_{R} \frac{P_{Q} Z}{B+P_{Q} Z}$ & progressive & neutral & regressive \\
$\eta_{H}>\eta_{R} \frac{P_{Q} Z}{B+P_{Q} Z}$ & ambiguous* & regressive & regressive \\
\hline${ }^{*}$ progressive if $\eta_{H}<\left(\eta_{R} \frac{P_{Q} Z}{B+P_{Q} Z}\right) f\left(\eta_{R}\right)$ & with $f\left(\eta_{R}\right)>1$ if $\beta<\xi ;$ and \\
$0<f\left(\eta_{R}\right) \leq 1$ if $\beta \geq \xi($ see details in Appendix $E)$. &
\end{tabular}

Proposition 3. The regressivity of an uncompensated increase in the green tax rate is stronger (weaker) when: the ratio $\frac{\beta}{\xi}$ is higher (lower), indicating that the the unemployment rate is above (under) the "optimal" level; the substitution effect that replaces high-skilled workers with low-skilled workers is higher (lower), such that the difference between the elasticity of the high-skilled labour supply with respect to green taxes and low-skilled sensitivity to the outside option $\eta_{H}-\frac{P_{Q} Z}{P_{Q} Z+B} \eta_{R}$ is higher (lower); the minimum level of consumption $\bar{D}$ is higher (lower).

\section{Revenue-Neutral Environmental Tax Reform}

We analyse a revenue-neutral green tax reform that increases the tax on the polluting good and reduces the income tax correspondingly. To that end, the government budget constraint (11) closes the model. We first characterize a uniform revenue-neutral reform and the necessary conditions for obtaining environmental and welfare dividends. After we analyse distributional properties of the tax reform, we discuss 
the implication of a reform that adopts a redistributive objective, using the progressivity of labour tax schemes.

\subsection{Specification of a uniform revenue-neutral tax reform}

We focus on balanced tax reforms, in which the government keeps the amount of government spending ex post unchanged $(d G=0),{ }^{26}$ and the tax policy maintains a constant amount of tax revenues. To describe a revenue-neutral green tax reform, we use the following expression:

$$
d G=G_{t_{D}}^{*} d t_{D}+G_{t_{H}}^{*} d t_{H}+G_{t_{L}}^{*} d t_{L}=0
$$

where $G_{t_{D}}^{*}$ denotes the marginal revenues from the tax on the dirty good, and $G_{t_{L}}^{*}$ and $G_{t_{H}}^{*}$ are the marginal revenues from the low- and high-skilled income taxes $t_{L}$ and $t_{H}$. Although we relax this assumption later, we first assume that $d t_{H}=d t_{L}=d t$, so the increase of the environmental tax rate is accompanied by a homogeneous variation of all labour tax rates. In other words, for the moment, we do not allow the government to assign revenues with a distributive objective. Moreover, we assume a Laffer-efficient tax system, $G_{t_{H}}^{*}>0, G_{t_{L}}^{*}>0, G_{t_{D}}^{*}>0$, so we can express $d t$ by $d t=-\frac{G_{t_{D}}^{*}}{G_{t_{H}}^{*}+G_{t_{L}}^{*}} d t_{D}<0$. Some algebra in Appendix F supports the following definition of a uniform revenue-neutral tax reform:

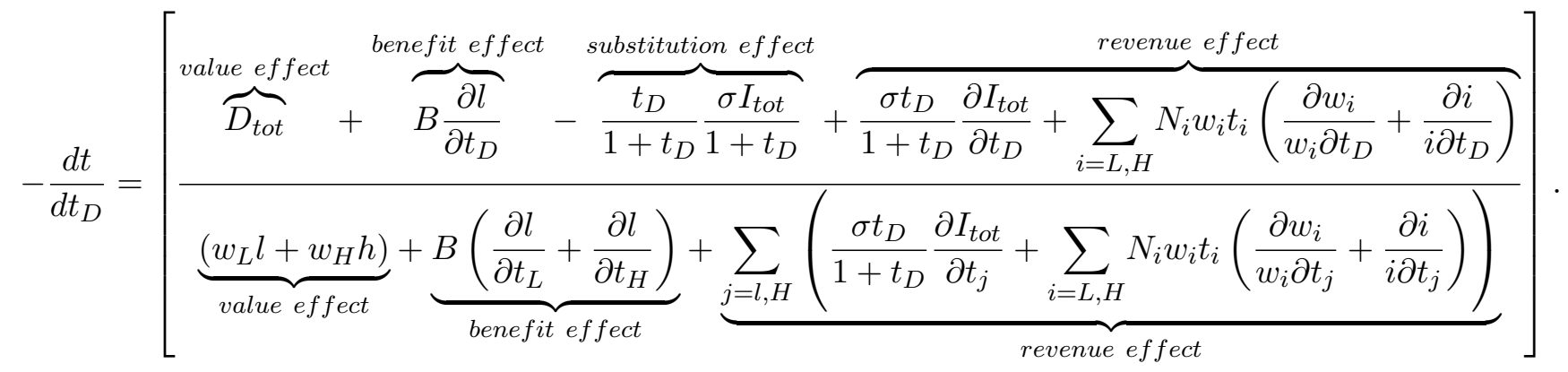

The numerator measures the effect of the change in the pollution tax rate on the share of its revenue that can be redistributed (after unemployment benefits have been paid). We distinguish both value effect (tax revenue increases with the pollution tax rate, for unchanged consumption $D_{t o t}$ ) and a tax base effect with three components. This tax base effect represents the possible erosion of the tax base: The increase of the pollution tax induces agents to substitute clean and polluting goods (substitution effect) and also affects wages and labour. Low-skilled employment decreases (Proposition 1), which increases the amount of unemployment benefits provided by the government (benefit effect). Changes in wages and labour also affect the total income of agents $\left(I_{t o t}=I_{L}+N I_{H}\right)$, leading to a decrease of total consumption and of

\footnotetext{
${ }^{26}$ Following double dividend literature (e.g., Bovenberg and de Mooij, 1994; Bovenberg and van der Ploeg, 1998), we introduce government spending and assume that its relative change is fixed. As Fullerton and Heutel (2007) explain, the government has a fixed targeted objective for public goods and uses its revenue to provide it. Because $G$ is exogenous, it impacts the agents utility level but not its variation due to the environmental tax reform, so we can exclude it from the utility function, without any loss of generality.
} 
$D_{t o t}$, according to its proportion of total unconstrained consumption $\left(\frac{\sigma t_{D}}{1+t_{D}}\right)$ (revenue effect).

The denominator measures the effect of the change in labour tax rates on their revenue. The value effect is proportional to labour revenues: Tax revenues increase with tax rates, for unchanged labour incomes. The tax base effect works in the opposite way: Total revenue and labour decrease (revenue effect) with labour tax rates. A decrease of low-skilled labour implies an increase of unemployment benefits (benefit effect).

The absolute variation of the labour tax rate $|d t|$ is an increasing function with respect to the subsistence level of the polluting good $\bar{D}$. It acts through the numerator. Augmenting $\bar{D}$ increases the value effect by increasing $D_{t o t}$, but it also minimizes the substitution effect and so the erosion of the tax base.

\subsection{Efficiency issue: environmental and welfare dividends}

We refer to Goulder's (1995) definition of a strong double dividend: an environmental dividend (i.e., a decrease in the consumption of the polluting good), together with a non-environmental welfare dividend (measured as an increase of the purchasing power, as represented by a negative marginal excess burden). From the equations for the marginal excess burden (15) and (16), and considering an egalitarian criterion in which the marginal excess burden of the economy is $d R_{t o t}=d R_{L}+N d R_{H}$, we can define the double dividend as follows:

Definition 2. The double dividend is obtained if two conditions are met:

1. $\Delta_{\text {tot }}^{P P}=-[\overbrace{\sum_{i=L, H}\left(N_{i} I_{i}\left[\tilde{w}_{i}-\frac{d t}{1-t_{i}}\right]\right)}^{\text {after-tax-wage-effect }}+\overbrace{P_{Q}\left(V_{L}^{E}-V_{L}^{U}\right) d l}^{\text {employment effect }}-\overbrace{D_{\text {tot }}}^{\text {consumption }} d t_{D}]<0$,

the revenue needed to compensate the variation of purchasing power must be negative.

2. $\Delta_{\text {tot }}^{e}=\left(-\frac{\partial \psi\left(D_{t o t}\right)}{\partial D_{t o t}} \frac{d D_{t o t}}{d t_{D}}\right)<0$, the total consumption of the polluting good must decrease.

Rewriting this definition, we show that a uniform revenue-neutral tax reform that increases the green tax rate $t_{D}$ and decreases both labour tax rates $d t_{i}$ equally, can lead to a strong double dividend if and only if:

$$
D_{t o t} d t_{D}+P_{Q}\left(Z d l+\varphi^{\prime}\left(H^{*}\right) N d H\right)<d I_{t o t}<\frac{I_{t o t}}{1+t_{D}} d t_{D}
$$

where $d I_{t o t}$ is the variation of total revenue of the agents. The proof is in Appendix G. This condition is intuitive: On the one hand, the positive impact on the total revenue of the agents must not be too high, so that polluting consumption $D_{i}$ can remain decreasing (right side of the inequality). On the other 
hand, the reform must compensate agents for their loss of consumption $D_{t o t}$ and their disutility of work expressed in monetary terms (left side of the inequality).

In this sense, our results do not differ from those of traditional studies of double dividend conditions, except that we include a subsistence level of the dirty good. Introducing $\bar{D}$ hampers the reconciliation of the environmental dividend with the non-environmental dividend. On the one hand, by decreasing the facility for substituting between clean and dirty goods, $\bar{D}$ makes the reform less efficient for achieving a better-quality environment. On the other hand, because of the low level of the substitution effect, the erosion of the tax base of the green tax is low, which leads to a larger tax shift. ${ }^{27}$ The tax system is thus more efficient. Global output and consumption of goods further increase. Which all the more counteracts the substitution effect induced by the green tax.

\subsection{Equity issue: distributive properties of the tax reform and the trade-off between efficiency and equity}

Proposition 4. If (i) the low-skilled labour market reflects the Hosios condition ( $\beta=\xi$ ), (ii) preferences for polluting goods are homothetic $(\bar{D}=0)$, (iii) the substitution between the types of labour is perfect $\left(\widetilde{p_{L}}=\widetilde{p_{H}}=0\right)$, and (iv) the tax system is Laffer-efficient, any uniform revenue-neutral tax reform appears regressive whatever the gain (or not) of the double dividend.

Proof. The green tax reform appears progressive if and only if $-\frac{d R_{L}}{I_{L}}>-\frac{d R_{H}}{I_{H}}$. Using the definition of the compensatory variations and noting that at the equilibrium $\widetilde{w_{H}}=\frac{-\alpha}{1-\alpha} \widetilde{p_{L}}$, we can rewrite this condition as:

$$
\left(\frac{l I_{L}^{E}}{I_{L}} \frac{1}{1-t_{L}}-\frac{1}{1-t_{H}}\right) d t<\left(\frac{l I_{L}^{E}}{I_{L}} \frac{\beta}{\xi} \frac{p_{L}}{w_{L}}+\frac{\alpha}{1-\alpha}\right) \widetilde{p_{L}}+\frac{l I_{L}^{E}}{I_{L}}\left[\frac{\xi-\beta}{\xi}\right] \frac{w_{R}}{w_{L}} \widetilde{w_{R}}-\left(\frac{D_{L}}{I_{L}}-\frac{D_{H}}{I_{H}}\right) d t_{D}
$$

Under conditions (i), (ii) and (iii) of Proposition 4, the right-hand side of the previous equation equals 0 . According to the Laffer-efficiency condition, $d t<0$. The initial progressivity of the tax system gives $\frac{l_{L}^{E}}{I_{L}}<1<\frac{1-t_{L}}{1-t_{H}}$. So, the left-hand side is always positive.

The green tax reform appears always regressive, even if there are some gains from the double dividend; redistributing through a uniform decrease of labour taxes is regressive in itself. In particular, unemployed workers are not compensated, which leads to $\left(\frac{l I_{L}^{E}}{I_{L}} \frac{1}{1-t_{L}}<\frac{1}{1-t_{H}}\right)$. The green tax reform thus may appear progressive if and only if the revenue effect through the change of productivities and reservation wages is sufficiently high to overcome the regressivity of the uses side effect and the regressivity of the uniform redistribution due to labour taxes.

\footnotetext{
${ }^{27}$ Demand for dirty goods is less elastic, so the Ramsey logic dictates that the optimal environmental tax must be set relatively high (Jacobs and van der Ploeg, 2019).
} 
Notably, in some cases, an uncompensated green tax may appear progressive initially, and an environmental tax reform could be regressive. Imagine that initially, $\bar{D}=0$ (no uses side effect), the ratio $\frac{\beta}{\xi}$ is low, and the elasticity of the high-skilled labour supply with respect to green taxes is lower than the low-skilled sensitivity of the outside option $\eta_{H}<\frac{P_{Q} Z}{P_{Q} Z+B} \eta_{R}$. According to Proposition 3, the initial impact of the raised environmental tax would induce a substitution effect between the different types of labour and an employment effect that are both progressive. Symmetrically, a reduction in the environmental tax would have a regressive impact. As mentioned, a uniform reduction in the labour tax rate is a regressive measure in itself, so a reduction in this tax does not have quite the same redistributive impact as a reduction in the environmental tax. But the substitution effect and employment effect go in the same direction, regardless of the tax being reduced. Thus, the more regressive a reduction in the environmental tax, the more regressive a reduction in the labour tax will be; the more gradual an increase in the environmental tax is, the more regressive a reduction in the labour tax will appear. Proposition 5 summarizes these results, and the proof is in Appendix H.

Proposition 5. If a uniform green tax reform succeeds in providing a double dividend, the reform tends to be even more progressive (regressive) when: (i) the ratio $\frac{\beta}{\xi}$ is higher (lower), such that the unemployment rate is above (below) the "optimal" level; (ii) the substitution effect that replaces high-skilled workers with low-skilled workers is higher (lower), such that the difference between the elasticity of the high-skilled labour supply with respect to green taxes and the low-skilled sensitivity of the outside option $\eta_{H}-\frac{P_{Q} Z}{P_{Q} Z+B} \eta_{R}$ is higher (lower); (iii) the minimum level of consumption $\bar{D}$ is lower (higher).

\subsection{Compensating low-skilled workers}

If an environmental tax reform appears regressive, is it possible to combine a redistributive objective with double dividend conditions? Similar to Chiroleu-Assouline and Fodha (2014)), we argue that the distributive properties of the labour tax policy could be an instrument for the fair internalization of environmental externalities. We propose using the progressivity of labour taxes to increase the progressivity of the environmental tax reform. Consequently, we allow $d t_{L}$ to differ from $d t_{H}$ as follows (with $-d a$ indicating the average labour tax rate variation):

$$
d t_{L}=-(1+\gamma) d a=-(1+\gamma)\left(\frac{G_{t_{D}}^{*}}{(1-\gamma) G_{t_{H}}^{*}+(1+\gamma) G_{t_{L}}^{*}}\right) d t_{D}
$$

and

$$
d t_{H}=-(1-\gamma) d a=-(1-\gamma)\left(\frac{G_{t_{D}}^{*}}{(1-\gamma) G_{t_{H}}^{*}+(1+\gamma) G_{t_{L}}^{*}}\right) d t_{D},
$$

where $\gamma$ represents the progressivity index. If $\gamma=0$, we the redistribution is proportional to revenue of the agents, $d t_{L}=d t_{H}=d t$. If $\gamma=1(\gamma=-1)$ the redistribution of the entire tax revenue goes to 
low-skilled workers (high-skilled workers).

Lemma 1. It is efficient to redistribute through $\gamma>0$ if and only if:

$$
\triangle(\gamma)=\Delta_{t o t}^{P P}(\gamma)-\Delta_{t o t}^{P P}(\gamma=0)<0 \Longleftrightarrow \frac{\partial \Delta_{t o t}^{P P}}{\partial t_{L}}>\frac{G_{t_{L}}^{*}}{G_{t_{H}}^{*}} \frac{\partial \Delta_{t o t}^{P P}}{\partial t_{H}} .
$$

See the proof in Appendix I. There is no trade-off between the efficiency of the reform and the use of progressivity if and only if the ratio of the marginal indirect utilities with respect to labour taxes is greater than the ratio of marginal revenues from labour taxes. Because $\triangle(\gamma)$ increases with the elasticity of high-skilled labour supply $\eta_{H}$, it is not possible to avoid the trade-off between the efficiency and equity of the reform when $\eta_{H}$ is really high.

Proposition 6. There is a threshold $\overline{\eta_{H}}$ under (above) which it is always (never) efficient to redistribute the revenue of environmental taxes by using a progressive fiscal index $\gamma>0$. In a particular case whith no substitution effect between low- and high-skilled labour, this threshold $\overline{\eta_{H}}$ is defined as:

$$
\begin{aligned}
\overline{\eta_{H}} & =\frac{1-t_{H}}{1-t_{L}} \frac{w_{R}}{w_{L}-w_{R}}\left(\frac{1-\frac{t_{D} \sigma}{1+t_{D}}}{\frac{t_{D} \sigma}{1+t_{D}}\left(1-t_{H}\right)+t_{H}}\right)\left[\frac{\left(1-t_{L}\right)(\beta-\xi)\left(w_{L}-w_{R}\right)+B(1-\xi) \beta}{w_{L} \xi+(\beta-\xi) w_{R}}\right] \\
& -\frac{1-t_{H}}{1-t_{L}} \frac{w_{R}}{w_{L}-w_{R}}\left(\frac{\frac{t_{D} \sigma}{1+t_{D}}\left(1-t_{L}\right)+t_{L}}{\frac{t_{D} \sigma}{1+t_{D}}\left(1-t_{H}\right)+t_{H}}\right)\left[\frac{(\xi-\beta) w_{L}-(1-\beta) \xi w_{R}}{w_{L} \xi+(\beta-\xi) w_{R}}\right]>0 .
\end{aligned}
$$

The proof is in Appendix I. The intuition of Proposition 6 holds that higher $\eta_{H}$ means that an increase of the progressivity index generates a greater decrease in the labour supply and production, which erodes the fiscal base. But in the low-skilled labour market, an increase of the initial progressive labour tax can act positively on employment, depending on the Hosios condition. Under the Hosios condition $(\beta=\xi)$, the two externalities on the low-skilled labour market exactly offset each other. So the more $\beta>\xi$, the more frictions in the low-skilled labour market are initially important, and the more a decrease in the low-skilled labour tax rate reduces the unemployment rate. The progressivity index can contribute to improve the efficiency of the tax system. Furthermore, $\overline{\eta_{H}}$ is such that the cost of progressivity (high-skilled labour supply) will equal its potential beneficial impact on the employment of low-skilled labour. Accordingly, $\overline{\eta_{H}}$ increases with the difference in $\beta-\xi$ (see details in Appendix I). It is also worth noting that $\overline{\eta_{H}}$ is lower when the initial index of progressivity $\frac{1-t_{L}}{1-t_{H}}$ is higher: The efficiency of the tax reform is constrained by the progressivity of the initial tax system. This result is in line with studies of progressivity and efficiency (e.g., Sørensen, 1999; Røed and Strøm, 2002). To illustrate the model arguments and provide some support for the generalization of Proposition 6, we next present simulations that highlight the trade-offs of first, second, and "third" dividends (inequalities). 


\section{Simulations}

We aim to provide some numerical illustrations of our theoretical model. We calibrate and simulate the economic and welfare consequences of an environmental tax reform, designed to include an increase in the progressivity labour taxes rate. Our approach is mainly theoretical, so some of our modelling choices are restrictive. We do not claim that the simulations are exhaustive or give a complete picture of the impacts of an environmental tax reform, ${ }^{28}$ but it may help readers understand the economic effects underlined previously, namely, substitution and consumption effects. We calibrate our model for the French case, then provide the interval of the plausible index of progressivity $(\gamma)$ that allows a double dividend to be obtained, while leaving the initial distributive characteristics of the economy unaffected after the reform. With these numerical illustrations, we also aim to identify key parameters of the economy that could affect the equity and performance of a green tax reform. Finally, we present a sensitivity analysis.

\subsection{Model calibration}

To close the numerical model, we specify the functional form of the matching function. Empirically, a reasonable approximation of the matching function in equation $\mathcal{M}$ is a Cobb-Douglas function, for which the index on each variable lies between 0 and 1. Following Pissarides (2000), we set the matching function to be $\mathcal{M}=\omega v^{1-\xi} 1^{\xi}$, where $\xi$ is the scale parameter of the matching function and always positive, such that $q(\theta)=\frac{\mathcal{M}}{v}=\omega \theta^{-\xi}$. The set of all parameters is given by $\left\{\eta_{H}, N, \beta, \alpha, \sigma, \xi, \omega, c, \bar{D}, B, Z\right.$, $\left.t_{H}, t_{L}, t_{D}\right\}$, and their values primarily come from existing sources. We refer to economic literature for the usual matching function parameters and parameters related to environmental externalities. We use the French National Institute of Statistics and Economic Studies (INSEE) database for accounting wage inequalities, the unemployment rate, unemployment benefits and the proportion of high-skilled workers in the economy $(N)$. The benchmark parameters of the model are summarized in Table 2.

\subsubsection{Households}

The choice of a Frisch form for the disutility of hours of work imposes a range of plausible values for the consumption-leisure substitution elasticity $\eta_{H}$, between 0.35 and 0.75 . These typical estimates from prior literature are meant to represent the effects of changes in the real wage on average hours worked. We first set our parameter $\eta_{H}$ to a value of 0.5 , a commonly used value that also is in line with estimates derived from microdata, as reported by Chetty et al. (2011). We define low-skilled workers as those who do no not attain tertiary education. According to the INSEE database, the share of low skilled workers is $66.5 \%$ in France. The corresponding value of $N$ is listed in Table 2. In turn, we choose the initial labour

\footnotetext{
${ }^{28}$ In particular, our model includes only one sector of production, such that the technology is identical for the production of clean and dirty goods.
} 
Table 2: Benchmark parameters values

\begin{tabular}{llc}
\hline & Parameters \\
$\beta:$ & bargaining power of the low-skilled workers & 0.5 \\
$\xi:$ & elasticity of the matching function & 0.5 \\
$\rho:$ & replacement rate & 0.35 \\
$\eta_{H}:$ & elasticity of the high-skilled labour supply & 0.5 \\
$N$ & number of high-skilled/low-skilled workers & 0.46 \\
$t_{H}:$ & high-skilled labour tax rate & 0.35 \\
$t_{L}:$ & low-skilled labour tax rate & 0.2 \\
$\alpha$ & share of low-skilled labour in production & 0.41 \\
$\sigma$ & share of polluting good in consumption & 0.35 \\
$t_{D}$ & green tax rate & 0.01 \\
\hline
\end{tabular}

tax rate in line with official labour taxes data. The unemployment benefit payment $B$ is a percentage of the low-skilled wage: $B=\rho W_{L}$, with $\rho$ defined as the replacement rate. ${ }^{29}$ We set $\rho=0.35$ (2016). We use the INSEE statistics to set the ratio of wages $\left(w_{L} / w_{H}\right)$ and the unemployment rate for the low skilled population $(u=10 \%$ in 2016). It implies calibrating the parameter $\alpha$ (share of low-skilled labour in total production) to match this ratio. The results are in Table 2.

\subsubsection{Matching function}

The parameter $\xi$ represents the elasticity of the matching function with respect to vacancies, set to 0.5 , or the average on the range of possible values identified by Pissarides (2000) and Petrongolo and Pissarides (2001). To ensure the Hosios condition in our benchmark calibration, we follow standard search models and set the bargaining power equal to the match elasticity $\beta=\xi=0.5$. We calibrate $\omega$ to fit the unemployment rates of low-skilled workers for France.

\subsubsection{Environment}

Following standard calibration in green taxation and double dividend literature (Cremer et al., 2003; Chiroleu-Assouline and Fodha, 2014), we specify the polluting good as an energy related good, which leads to an average share of of total output, such that $\sigma=0.35$ if we assume $\bar{D}=0$. In the following, $\bar{D}$ varies between $0 \%$ and $50 \%$ of consumption of dirty goods by low-skill households (we recalibrate $\sigma$ accordingly). The environmental tax rate for the French system corresponds closely to the budget of the French Environmental and Energy Management Agency (ADEME), which until 2017 was entirely financed by environmental tax revenues. Similar to Chiroleu-Assouline and Fodha (2014), we set $t_{D}=0.01$.

\footnotetext{
${ }^{29}$ We use the replacement rate to calibrate the unemployment benefits of the steady-state, whereas tax reform is analysed with fixed nominal unemployment benefits.
} 


\subsection{Design of an equity-neutral tax reform}

We define the corresponding index of progressivity $\gamma$ to obtain:

1. A reform that reduces the environmental damage and satisfies the first dividend hypothesis: $\gamma^{E}$ is the upper bound (a higher $\gamma$ would allow low-skilled households to increase their consumption, including of dirty goods).

2. A reform that increases global non-environmental welfare (i.e., purchasing power) and thus satisfies the second dividend: $\gamma^{P}$ is the lower bound (a lower $\gamma$ would not increase aggregate purchasing power sufficiently).

3. A reform that leaves the initial inequalities unaffected: $\gamma^{I}$ is the lower bound (a lower $\gamma$ would not be sufficient to ensure compensation of poorer households).

Figure 1 represents the three crucial conditions for an efficient and acceptable environmental tax reform as functions of the progressivity index $\gamma$ of the reform (x-axis): the "environmental dividend condition", defined as the decrease of polluting good consumption (dotted line), the "efficiency line", defined as the variation of global welfare (bold line), and the "progressivity line", which stands for the progressivity of the reform (dashed line). The intersection of these curves with the horizontal line $y=0$ gives the thresholds $\left(\gamma^{E}, \gamma^{P}, \gamma^{I}\right)$.

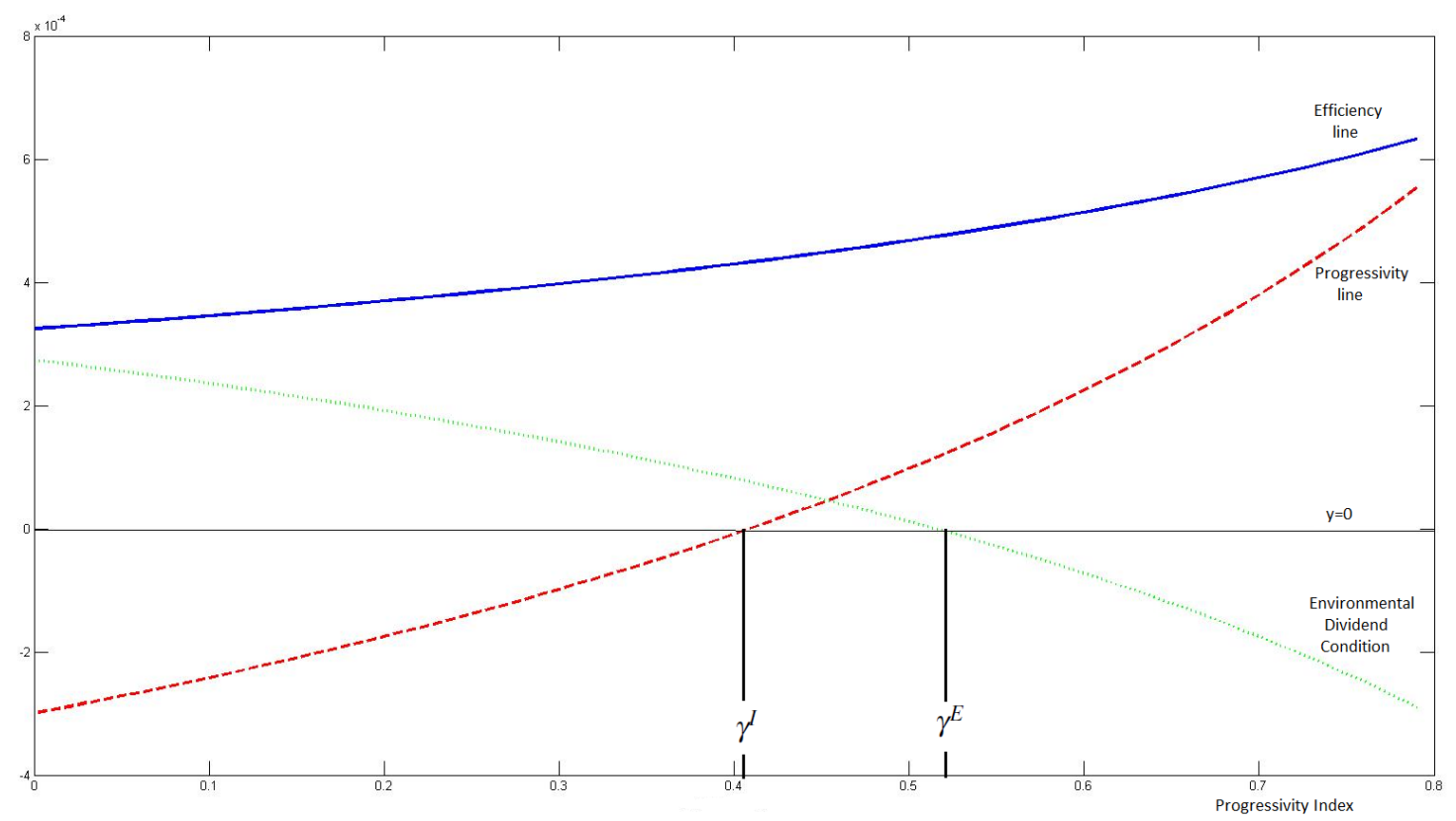

Figure 1: Environmental dividend, efficiency and equity according to labour tax progressivity

An increase in the progressivity index appears always better for the efficiency of the reform (efficiency line is a positive increasing function). The efficiency dividend is obtained for any positive progressivity 
index (more precisely, for any $\gamma>-0,22$ ). These results are in line with Bayındır-Upmann and Raith (2003). We find that a uniform decrease in the labour tax rate plausibly leads to a positive aggregate income effect. As a consequence, environmental quality turns out to be lower than before. Finally, the first dividend may be the most difficult to achieve. This is all the more so as the strengthening of the progressivity index enhances the effectiveness of the reform (Proposition 6). Typically progressivity increases the employment rate and tax base of the reform, leading to a more efficient allocation. The trade-off between equity and the environment is now more relevant than ever.

This result would not hold though if the labour supply elasticity of high-skilled labour $\left(\eta_{H}\right)$ were much higher (see the sensitivity test in Appendix J). ${ }^{30}$ In this case, the shape of the efficiency curve would change, in line with Proposition 6 . There exists a threshold $\left(\overline{\eta_{H}}\right)$ under which there is no trade-off between efficiency and progressivity.

With regard to equity problems, Figure 1 shows a threshold level $\gamma^{I}$ for which the environmental tax reform is neutral in terms of redistribution, $\gamma^{I}=0,42$. If $\gamma$ is above (below) this level, the reform will appear progressive (regressive). Even with a homothetic utility function $(\bar{D}=0)$, a positive index of progressivity is always needed to leave global economic welfare unaffected, due to the "income sources side effect". The green tax reform associated with a uniform decrease of the labour tax rate is still regressive, because of low-skilled labour market externalities. The environmental dividend curve also shows how the reduction of environmental damage varies with progressivity. The more the progressivity index increases, the less the reform can decrease pollution. Basically, we find a trade-off between progressivity and obtaining the first dividend, which follows from two facts. Overall economic welfare (or purchasing power) increases with the index of progressivity (traditional trade-off between the first and second dividend). But by changing the distributive characteristics of the economy, it leaves poorer households better off, whereas the share of dirty consumption in their total income is higher (Stones-Geary preferences).

Additional simulations reveal a range $\gamma \in\left[\gamma^{I} ; \gamma^{E}\right]$ for which the environmental reform generates welfare gains that are Pareto improving. We summarize the simulation results in the following Table.

The first column reflects business as usual, or the benchmark parameters in Table 2. To illustrate how our results depend on specific parameter assumptions, in Columns $2-5$ we present the thresholds of the progressivity index $\gamma$ for different key parameter values. In all the simulations, we recalibrate disutility from work and unemployment benefits to maintain a steady-state unemployment rate of $10 \%$ before the reform. Column 2 indicates the incidence of bargaining power keeping $\xi$ constant. Bargaining power determines whether firms or workers bear a larger share of the incidence of the emissions tax. If employers have more bargaining power - such that the employer gets a larger share of the surplus from a job match

\footnotetext{
${ }^{30}$ They also might change in the opposite case according to the Hosios conditions $(\beta<\xi)$. Typically, $\beta<\xi$ means the economy falls under the "optimal" level of unemployment, and an increase of the progressivity index by increasing employment may be counterproductive.
} 
Table 3: The trade-off between the environmental and equity goals

\begin{tabular}{ccccc}
\hline & $\begin{array}{c}\text { Baseline scenario: } \\
\text { Benchmark } \\
\text { parameter values }\end{array}$ & $\begin{array}{c}\beta=0.75 \\
\text { Stronger } \\
\text { bargaining power }\end{array}$ & $\begin{array}{c}\eta_{H}=0.8 \\
\text { Higher high-skilled } \\
\text { supply elasticity }\end{array}$ & $\begin{array}{c}\bar{D}=0.5(\sigma=0.45) \\
\text { Higher minimum } \\
\text { of dirty good }\end{array}$ \\
\hline$\gamma^{E}$ & 0.58 & 0.61 & 0.63 & 0.52 \\
$\gamma^{I}$ & 0.42 & 0.32 & 0.35 & 0.44 \\
\hline
\end{tabular}

If the progressivity $\gamma>\gamma^{E}$ there is no environmental dividend.

If the progressivity index $\gamma<\gamma^{I}$ the reform appears regressive.

- the initial green tax incidence induces higher unemployment impacts. In contrast, redistributing green tax revenue by decreasing the labour income tax generates higher employment impacts. In the case of a double dividend, the second effect exceeds the first one, and a lower progressivity index is needed to achieve reform progressivity. Column 3 shows the impact of high-skilled labour elasticity $\left(\eta_{H}\right)$ on the efficiency and equity of the reform. When $\eta_{H}$ becomes higher, progressivity leads to more inefficiency. But the substitution effect that replaces high-skilled workers with low-skilled workers also becomes stronger, which benefits low-skilled workers. Thus, it becomes easier to reach a neutral redistribution ( $\gamma^{I}$ decreases). Due to the larger inefficiency of the economy, the environmental objective is easier to reach ( $\gamma^{E}$ increases). Finally, the last column indicates that environmental and equity objectives become even more difficult to reconcile when the minimum consumption of the dirty good increases. The higher the minimum of dirty consumption $(\bar{D})$ is, the lower the magnitude of the interval $\left[\gamma^{I} ; \gamma^{E}\right]$ is. That is, $\gamma^{I}$ will increase to offset the increase of the regressivity of the green tax, due to the uses side effect. At the same time, $\gamma^{E}$ will decrease: Increasing the amount of the minimum of dirty good consumption reduces the elasticity of substitution between the dirty and clean goods. It thus becomes harder to reduce pollution.

\section{Conclusions}

Can consumption of polluting goods be reduced without harming employment or placing undue burdens on poor people? Might a pollution tax be combined with income tax reductions to ensure a progressive outcome? In this paper, we investigate the distributional and efficiency consequences of an environmental tax reform, using an analytical general equilibrium model with imperfect, heterogeneous labour markets and non-homothetic preferences. This model contains several features that help identify the key components of the regressivity/progressivity of the environmental tax. Our specification of utility, as a Stone-Geary function, allows us to represent dirty goods as necessities and emphasizes the importance of the magnitude of the subsistence level of consumption of polluting goods, like energy products. An increase of this subsistence level always leads to regressivity of the environmental tax through a uses side effect of income: The share of dirty goods as a proportion of total consumption is higher for low-skilled, 
compared with high-skilled, labour, and so is the tax burden. Moreover, the asymmetry between low- and high-skilled labour markets sheds light on the difference between high- and low-skilled wage formations, which is crucial to the distributional properties of green tax analyses. If low-paid employment is more responsive than high-paid employment (i.e., high-skilled labour supply is relatively low compared with low-skilled labour demand sensitivity), an uncompensated environmental tax can be progressive, acting through a revenue effect that reflects the effect on the sources side effect of income. However, the revenue effect of the revenue-neutral environmental reform, when the green tax is redistributed through variation in labour tax rates, is more ambiguous and depends on the magnitude of the efficiency of the reform. If the reform appears regressive, the gains from the double dividend can be made Pareto improving by using a redistributive, non-linear income tax if the redistribution is initially not too large, and if the subsistence level of polluting consumption is not too high. Moreover, the use of a non-linear income tax acts on unemployment, which can moderate the trade-off between equity and efficiency. We finally provide numerical illustrations and a sensitivity analysis that support the feasibility of such an environmental tax reform for the French case.

\section{Appendix}

\section{A Wage Bargaining}

The wages of low-skilled workers are determined as: $w_{L}=\operatorname{argmax}\left\{\left(Q^{*}\left(I_{L}^{E}\right)-\left[Q^{*}\left(I_{L}^{U}\right)+Z\right]\right)^{\beta}\left(\frac{\partial f}{\partial l}-w_{L}\right)^{1-\beta}\right\}$. The first-order condition gives: $\beta\left[\frac{\left(1-t_{L}\right)}{P_{Q}\left[Q_{L}^{E *}-Q_{L}^{U *}-Z\right]}\right]-(1-\beta)\left[\frac{1}{\frac{\partial f}{\partial l}-w_{L}}\right]=0$. With Equation 7 ,

$$
\frac{P_{Q}\left[Q_{L}^{E *}-\left(Q_{L}^{U *}+Z\right)\right]}{\left(1-t_{L}\right)}=\frac{\beta}{1-\beta} *\left[\frac{\partial f}{\partial l}-w_{L}\right]=\frac{\beta}{1-\beta} *\left[\frac{c}{q(\theta)}\right] \text {. }
$$

Recall that $w_{R}$ is defined as $w_{L}$ such that $Q^{*}\left(I_{L}^{E}\right)=\left[Q^{*}\left(I_{L}^{U}\right)+Z\right]$, which gives: $w_{R}=\frac{B+P_{Q} Z}{1-t_{L}}=$ $\frac{P_{Q}\left[Q^{*}\left(I_{L}^{U}\right)+Z\right]}{1-t_{L}}$. Then we can rewrite Equation A. 1 as:

$$
\frac{P_{Q}\left[Q^{*}\left(I_{L}^{E}\right)-\left(Q_{L}^{U *}+Z\right)\right]}{\left(1-t_{L}\right)}=\frac{P_{Q}\left[Q^{*}\left(I_{L}^{E}\right)\right]}{\left(1-t_{L}\right)}-w_{R}=w_{L}-w_{R}=M
$$

Equations A. 1 and A. 2 lead to $w_{L}=w_{R}+\beta\left(p_{L}-w_{R}\right)$.

\section{B Comparative statics}

Table B.1 contains the log-linearized model. The solutions are in Table B.2. The tilde $(\sim)$ denotes percentage changes relative to initial values, such that $\tilde{l} \equiv \frac{d l}{l}$. Exceptions to this definition are separately indicated. 
Table B.1: Log-linearized model

$$
\begin{array}{ll}
\text { Low-skilled labour } & \tilde{l}=(1-\xi) * \tilde{\theta}=\tilde{y}-\widetilde{p_{L}} \\
\text { Job creation condition } & \widetilde{p_{L}}=\frac{w_{L}}{p_{L}} * \widetilde{w_{L}}+\frac{c}{q(\theta)} \frac{\xi}{p_{L}} * \widetilde{\theta} \\
\text { Wage mark-up equation } & \widetilde{w_{L}} w_{L}=\beta \widetilde{p_{L}} p_{L}+[1-\beta] \widetilde{w_{R}} w_{R} \\
\text { High-skilled labour demand } & \tilde{H}=\eta_{H} *\left[\widetilde{p_{H}}-d \tau_{H}\right]=\tilde{y}-\widetilde{p_{H}} \\
\text { Production } & \tilde{y}=\alpha \tilde{l}+(1-\alpha) \tilde{h} \Leftrightarrow \widetilde{p_{H}}=-\frac{\alpha}{1-\alpha} \widetilde{p_{L}}
\end{array}
$$

Table B.2: Solutions of the Log-linearized model

$$
\begin{aligned}
& \text { Low-skilled labour } \\
& \tilde{l}=-\mu_{L}\left[\widetilde{w_{R}} \frac{w_{R}}{p_{L}}+\eta_{H}\left(\alpha \widetilde{w_{R}} \frac{w_{R}}{p_{L}}+(1-\alpha) d \tau_{H}\right)\right] \\
& \text { High-skilled labour } \\
& \tilde{h}=\tilde{H}=-\mu_{H}\left[d \tau_{H}+\eta_{L}\left(\alpha \widetilde{w_{R}} \frac{w_{R}}{p_{L}}+(1-\alpha) d \tau_{H}\right)\right] \\
& \text { Production } \\
& \tilde{y}=-\left[\alpha \mu_{L} \widetilde{w_{R}} \frac{w_{R}}{p_{L}}\left(1+\eta_{H}\right)+(1-\alpha) \mu_{H} d \tau_{H}\left(1+\eta_{L}\right)\right] \\
& \text { Low-skilled productivity } \quad \widetilde{p_{L}}=(1-\alpha) \frac{\mu_{L}}{\eta_{L}}\left[\eta_{R} \widetilde{w_{R}}-\eta_{H} d \tau_{H}\right] \\
& \text { High-skilled productivity } \widetilde{p_{H}}=-(\alpha) \frac{\mu_{H}}{\eta_{H}}\left[\eta_{R} \widetilde{w_{R}}-\eta_{H} d \tau_{H}\right] \\
& \text { Low-skilled wage } \quad \widetilde{w_{L}}=\frac{p_{L}}{w_{L}}\left[\left((1-\beta)+(1-\alpha) \beta \mu_{L}\right) \widetilde{w_{R}} \frac{w_{R}}{p_{L}}+-\beta\left((1-\alpha) \mu_{H}\right) d \tau_{H}\right]
\end{aligned}
$$

We denote $\widetilde{w_{R}}=\left[\frac{d t_{L}}{1-t_{L}}+\frac{P_{Q} Z}{w_{R}\left(1-t_{L}\right)} \frac{\sigma}{1+t_{D}} d t_{D}\right]$ as the variation of the reservation wage with the tax rate variations $d t_{D}$ and $d t_{L}$, as well as $d \tau_{H}=\frac{\sigma}{1+t_{D}} * d t_{D}+\frac{1}{1-t_{H}} * d t_{H}$. We define $0<\mu_{H}=\frac{\eta_{H}}{1+(1-\alpha) \eta_{L}+\alpha \eta_{H}}=$ $\frac{\eta_{H}}{\eta_{L}} \mu_{L}<1$, and $\eta_{L}=\frac{1-\xi}{\xi}\left[\frac{p_{L}}{p_{L}-w_{R}}\right]$ is the elasticity of the low-skilled labour to productivity $p_{L}$.

\section{Proposition 1}

If utilities do no depend on leisure, $Z=0$ and $\varphi(H)=0$ (meaning that the labour supply of high skilled is exogenous). In this case, $\widetilde{w_{R}}$ and then $\widetilde{l}, \widetilde{h}$ do not depend on $d t_{D}$. There is no price effect.

If utilities depend on leisure, according to Table B.2 (Equations I and II), both $\widetilde{l}$ and $\widetilde{h}$ depend negatively on $\widetilde{w_{R}}$ and $\widetilde{d \tau_{H}}$. But $\widetilde{w_{R}}=\left[\frac{d t_{L}}{1-t_{L}}+\frac{P_{Q} Z}{w_{R}\left(1-t_{L}\right)} \frac{\sigma}{1+t_{D}} d t_{D}\right]$, and $\tau_{H}=\frac{\sigma}{1+t_{D}} * d t_{D}+\frac{1}{1-t_{H}} * d t_{H}$ increases in green taxes rate. Then, a higher green tax decreases $\widetilde{l}$ and $\widetilde{h}$. Consequently $\widetilde{y}$ decreases (obvious from 


\section{Equation 5).}

$\frac{\widetilde{p_{L}}}{p_{H}}=\widetilde{p_{L}}-p_{H}$. Or $\widetilde{p_{H}}=-\frac{\alpha}{1-\alpha} \widetilde{p_{L}}$. Then $\frac{\widetilde{p_{L}}}{p_{H}}=\widetilde{p_{L}}\left(\frac{1}{1-\alpha}\right)$. It is positive if $p_{L}>0 \Leftrightarrow \eta_{R} \widetilde{w_{R}}>\eta_{H} d \tau_{H}$. Using the definitions of $w_{R}, \tilde{w_{R}}$, and $d t_{H}=d t_{L}=0$ we obtain $\eta_{H}<\eta_{R} \frac{P_{Q} Z}{w_{R}\left(1-t_{L}\right)} \Leftrightarrow \frac{\eta_{H}}{\eta_{R}}<\frac{P_{Q} Z}{P_{Q} Z+B}=p_{1}$.

\section{The compensatory income variation}

Determine the compensatory income variation of low-skilled workers:

$$
\begin{gathered}
d V_{L}=0 \Leftrightarrow(1-l) d V_{L}^{U}+l d V_{L}^{E}+\left(V_{L}^{E}-V_{L}^{U}\right) d l=0 \\
\Leftrightarrow(1-l) \frac{\partial V_{L}^{U}}{\partial C_{L}} d C_{L}^{U}+l \frac{\partial V_{L}^{E}}{\partial C_{L}} d C_{L}^{E}+(1-l) \frac{\partial V_{L}^{U}}{\partial D_{L}} d D_{L}^{U}+l \frac{\partial V_{L}^{E}}{\partial D_{L}} d D_{L}^{E}+\left(V_{L}^{E}-V_{L}^{U}\right) d l+\frac{\partial V_{L}}{\partial D_{t o t}} d D_{t o t}=0 .
\end{gathered}
$$

Using the first-order conditions of consumer's program, we can determine

$d V_{L}=0 \Leftrightarrow \frac{1}{P_{Q}}\left[(1-l) d C_{L}^{U}+l d C_{L}^{E}\right]+\frac{\left(1+t_{D}\right)}{P_{Q}}\left[(1-l) d D_{L}^{U}+l d D_{L}^{E}\right]+\left(V_{L}^{E}-V_{L}^{U}\right) d l+\frac{\partial V_{L}}{\partial D_{t o t}} d D_{\text {tot }}=0$.

By differentiating the budget constraint of low-skill households we obtain:

$$
\begin{aligned}
{\left[I_{L}^{E}-B\right] d l+} & {\left[\left(1+t_{D}\right)\left((1-l) d D_{L}^{U}+l d D_{L}^{E}\right)+(1-l) d C_{L}^{U}+l d C_{L}^{E}\right]+d t_{D} D_{L} } \\
& =\left[w_{L}\left(1-t_{L}\right)-B\right] d l+I_{L}^{E} l\left(\widetilde{w_{L}}-\frac{d t_{L}}{1-t_{L}}\right)+d R_{L} .
\end{aligned}
$$

Using the definition of the compensatory income variation, we get:

$$
d R_{L}=-\left[I_{L}^{E} l\left(\widetilde{w_{L}}-\frac{d t_{L}}{1-t_{L}}\right)+P_{Q}\left(V_{L}^{E}-V_{L}^{U}\right) d l-D_{L} d t_{D}-\frac{\partial V_{L}}{\partial D_{t o t}} P_{Q} d D_{t o t}\right]
$$

Remember that $M=w_{L}-w_{R}=\frac{\beta}{1-\beta} \frac{c}{q(\theta)}$ (Equation 9). Thus we can express $\widetilde{l}=\frac{1-\xi}{\xi} \frac{\beta}{1-\beta}\left(\frac{p_{L} \widetilde{p_{L}}-w_{L} \widetilde{w_{L}}}{M}\right)$. Noting that $P_{Q}\left(V_{L}^{E}-V_{L}^{U}\right) d l=\left(\frac{w_{L}-w_{R}}{w_{L}}\right) l I_{L}^{E} \widetilde{l}$ and using the definition of $\widetilde{w_{L}}$, we obtain:

$$
d R_{L}=-\left[l I_{L}^{E}\left(\left[\frac{\beta}{\xi} \frac{p_{L}}{w_{L}} \widetilde{p}_{L}+\left[\frac{\xi-\beta}{\xi}\right] \frac{w_{R}}{w_{L}} \widetilde{w}_{R}\right]-\frac{d t_{L}}{1-t_{L}}\right)-D_{L} d t_{D}-\frac{\partial V_{L}}{\partial D_{t o t}} P_{Q} d D_{t o t}\right]
$$

\section{E Proposition 3: The regressivity of an uncompensated green tax}

An increase of an uncompensated green tax appears regressive if and only if, when $d t_{D}>0$ and $d t_{L}=d t_{H}=0: \frac{\Delta_{H}^{P P}}{I_{H} d t_{D}}<\frac{\Delta_{L}^{P P}}{I_{L} d t_{D}}$. Combining with Equations 15 and 17 leads to:

$$
\left[\frac{d w_{H}}{w_{H} d t_{D}}-\frac{D_{H}}{I_{H}}\right]>\left[\frac{I_{L}^{E} l}{I_{L}}\left(\frac{\beta}{\xi} \frac{p_{L}}{w_{L}} \frac{d p_{L}}{p_{L} d t_{D}}\right)+\frac{I_{L}^{E} l}{I_{L}}\left[\frac{\xi-\beta}{\xi}\right] \frac{w_{R}}{w_{L}} \frac{d w_{R}}{w_{R} d t_{D}}-\frac{D_{L}}{I_{L}}\right]
$$


Because of the functional form of the consumption utility, $\frac{D_{H}}{I_{H}}-\frac{D_{L}}{I_{L}}=(1-\sigma) \bar{D}\left[\frac{1}{I_{H}}-\frac{1}{I_{L}}\right] \leq 0, \forall \bar{D} \geq 0$. In the case that $\bar{D}=0$, the definition of regressivity is equivalent to

$$
\begin{gathered}
{\left[\frac{d w_{H}}{w_{H} d t_{D}}\right]>\left[\frac{I_{L}^{E} l}{I_{L}}\left(\frac{\beta}{\xi} \frac{p_{L}}{w_{L}} \frac{d p_{L}}{p_{L} d t_{D}}\right)+\frac{I_{L}^{E} l}{I_{L}}\left[\frac{\xi-\beta}{\xi}\right] \frac{w_{R}}{w_{L}} \frac{d w_{R}}{w_{R} d t_{D}}\right]} \\
\Leftrightarrow\left[\alpha \frac{\mu_{H}}{\eta_{H}}\left[\eta_{H} \frac{d \tau_{H}}{d t_{D}}-\eta_{R} \frac{d w_{R}}{w_{R} d t_{D}}\right]\right]>\left[\frac{I_{L}^{E} l}{I_{L}}\left(\frac{\beta}{\xi} \frac{p_{L}}{w_{L}}(1-\alpha) \frac{\mu_{L}}{\eta_{L}}\left[\eta_{R} \frac{d w_{R}}{w_{R} d t_{D}}-\eta_{H} \frac{d \tau_{H}}{d t_{D}}\right]\right)+\frac{I_{L}^{E} l}{I_{L}}\left[\frac{\xi-\beta}{\xi}\right] \frac{w_{R}}{w_{L}} \frac{d w_{R}}{w_{R} d t_{D}}\right] .
\end{gathered}
$$

By multiplying both sides by $\left(1+\alpha \eta_{H}+(1-\alpha) \eta_{L}\right)$, replacing $d \tau_{H}$ and $\frac{d w_{R}}{w_{R} d t_{D}}$, dividing by $\frac{t_{D} \sigma}{1+t_{D}}$, and expressing everything in terms of $\eta_{R}$, we obtain:

$$
\begin{aligned}
\eta_{H} & >\frac{P_{Q} Z}{P_{Q} Z+B} \eta_{R}\left[\frac{\alpha+\frac{I_{L}^{E} l}{I_{L}} * \frac{1}{\beta(1-\xi)+\xi \eta_{R}}\left[(1-\alpha)\left(1-\xi+\xi \eta_{R}\right)+(\xi-\beta) \eta_{R}\right]}{\alpha+\frac{I_{L}^{E} l}{I_{L}} * \frac{1}{\beta(1-\xi)+\xi \eta_{R}}\left[(1-\alpha)\left(1-\xi+\xi \eta_{R}\right)-(\xi-\beta) \eta_{R} \frac{P_{Q} Z}{P_{Q} Z+B}\right]}\right] \\
& >\frac{P_{Q} Z}{P_{Q} Z+B} \eta_{R}\left[f\left(\eta_{R}\right)\right] .
\end{aligned}
$$

If $\xi=\beta$ (i.e., the Hosios condition is verified), $f\left(\eta_{R}\right)=1$. If $\xi>\beta(\xi<\beta), f\left(\eta_{R}\right)>1\left(0<f\left(\eta_{R}\right)<1\right)$. According to Proposition 1, a higher uncompensated green tax raises unemployment $\frac{d l}{d t_{D}}<0$. If $\frac{d w_{L}}{w_{L} d t_{D}}<$ 0 , (which implies necessarily that $\frac{d w_{H}}{w_{H} d t_{D}}>0$ ),

$$
[\underbrace{\frac{d w_{H}}{w_{H} d t_{D}}}_{>0}]>[\underbrace{\frac{l I_{L}^{E}}{I_{L}}\left(\frac{d w_{L}}{w_{L} d t_{D}}\right)}_{<0}+\underbrace{\frac{P_{Q}\left(V_{L}^{E}-V_{L}^{U}\right) \frac{d l}{d t_{D}}}{I_{L}}}_{<0}]+[\underbrace{\frac{D_{H}}{I_{H}}-\frac{D_{L}}{I_{L}}}_{<0}] .
$$

In this case, a higher uncompensated green tax is unambiguously regressive.

\section{F Revenue-neutral tax reform}

Recall the government budget constraint (11): $G+(1-l) B=l w_{L} t_{L}+N H w_{H} t_{H}+t_{D} D_{t o t}$. Replacing $D_{t o t}$ and using $h=H N$, we obtain $G=l w_{L} t_{L}+h w_{H} t_{H}+t_{D}\left(\frac{\sigma}{1+t_{D}} I_{t o t}+(N+1)(1-\sigma) \bar{D}\right)$. We want to identify $G_{t_{D}}^{*}, G_{t_{L}}^{*}$, and $G_{t_{H}}^{*}$.

$G_{t_{D}}^{*}=\frac{d G}{d t_{D}}=D_{t o t}+l w_{L} t_{L}\left(\frac{\partial w_{L}}{w_{L} \partial t_{D}}+\frac{\partial l}{l \partial t_{D}}\right)+h w_{H} t_{H}\left(\frac{\partial w_{H}}{w_{H} \partial t_{D}}+\frac{\partial H}{H \partial t_{D}}\right)+B \frac{\partial l}{\partial t_{D}}+t_{D} \frac{\sigma}{1+t_{D}}\left(-\frac{I_{t o t}}{1+t_{D}}+\frac{\partial I_{t o t}}{\partial t_{D}}\right)$, $G_{t_{L}}^{*}=\frac{d G}{d t_{L}}=w_{L} l+l w_{L} t_{L}\left(\frac{\partial w_{L}}{w_{L} \partial t_{L}}+\frac{\partial l}{l \partial t_{L}}\right)+h w_{H} t_{H}\left(\frac{\partial w_{H}}{w_{H} \partial t_{L}}+\frac{\partial H}{H \partial t_{L}}\right)+B \frac{\partial l}{\partial t_{L}}+t_{D} \frac{\sigma}{1+t_{D}} \frac{\partial I_{t o t}}{\partial t_{L}}$,

$G_{t_{H}}^{*}=\frac{d G}{d t_{H}}=w_{H} h+l w_{L} t_{L}\left(\frac{\partial w_{L}}{w_{L} \partial t_{H}}+\frac{\partial l}{l \partial t_{H}}\right)+h w_{H} t_{H}\left(\frac{\partial w_{H}}{w_{H} \partial t_{H}}+\frac{\partial H}{H \partial t_{H}}\right)+B \frac{\partial l}{\partial t_{H}}+t_{D} \frac{\sigma}{1+t_{D}} \frac{\partial I_{t o t}}{\partial t_{H}}$.

Finally, 


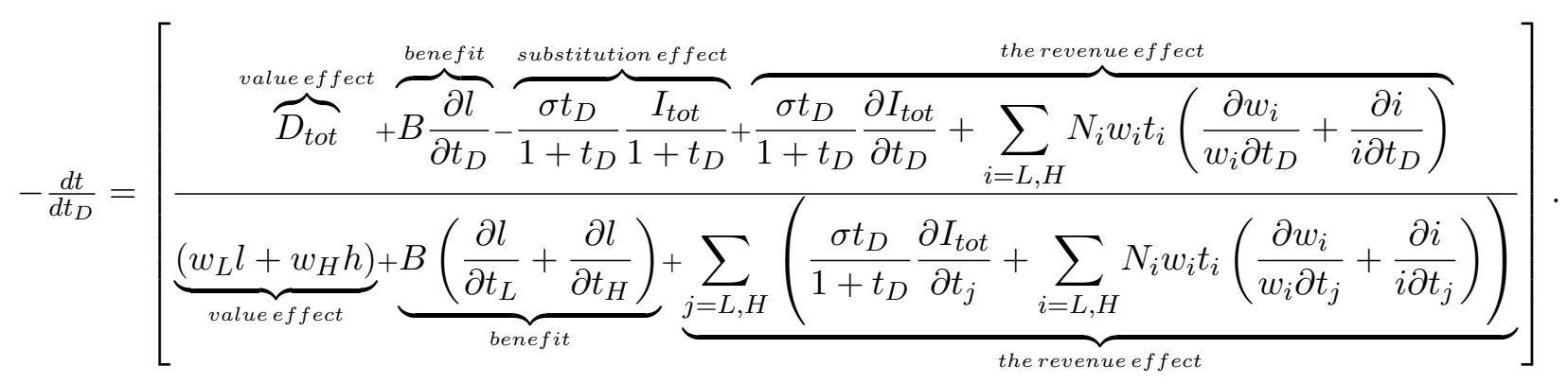

\section{G Double dividend}

Condition for obtaining the first dividend:

$d D_{\text {tot }}<0 \Longleftrightarrow\left(-\left[\frac{\sigma}{\left(1+t_{D}\right)^{2}} * I_{t o t}\right] d t_{D}+\left[\frac{\sigma}{\left(1+t_{D}\right)} * d I_{t o t}\right]\right)<0$.

Therefore, $d D_{\text {tot }}<0 \Longleftrightarrow \frac{\sigma}{\left(1+t_{D}\right)} *\left[\left(1+t_{D}\right) d I_{\text {tot }}-I_{\text {tot }} \frac{d t_{D}}{1+t_{D}}\right]<0 \Longleftrightarrow\left[d I_{\text {tot }}<I_{\text {tot }} \frac{d t_{D}}{\left(1+t_{D}\right)}\right]$.

Condition for obtaining the second dividend: $\Delta_{\text {tot }}^{P P}<0 \Longleftrightarrow-\left[\left(d R_{L}+\Delta_{L}^{e}\right)+N\left(d R_{H}+\Delta_{H}^{e}\right)\right]>0$, and we know that

$$
\begin{aligned}
& -\left(d R_{L}+\Delta_{L}^{e}\right)=l I_{L}^{E}\left(\widetilde{w_{L}}-\frac{d t_{L}}{1-t_{L}}\right)+P_{Q}\left(V_{L}^{E}-V_{L}^{U}\right) d l-D_{L} d t_{D}=d I_{L}-P_{Q} Z d l-D_{L} d t_{D}, \\
& -\left(d R_{H}+\Delta_{H}^{e}\right)=I_{H}\left(\widetilde{w_{H}}-\tilde{t_{H}}\right)-D_{H} d t_{D}=d I_{H}-P_{Q}\left(\varphi^{\prime}\left(H^{*}\right)\right) d H-D_{H} d t_{D} .
\end{aligned}
$$

Combining the last two equations, the condition for the second dividend is

$D_{t o t} d t_{D}+P_{Q} Z d l+P_{Q}\left(\varphi^{\prime}\left(H^{*}\right)\right) N d H<d I_{t o t}$.

\section{H Proposition 5}

The proof flows from Equation (19):

$$
\left(\frac{l I_{L}^{E}}{I_{L}} \frac{1}{1-t_{L}}-\frac{1}{1-t_{H}}\right) d t<\left(\frac{l I_{L}^{E}}{I_{L}} \frac{\beta}{\xi} \frac{p_{L}}{w_{L}}+\frac{\alpha}{1-\alpha}\right) \widetilde{p_{L}}+\frac{l I_{L}^{E}}{I_{L}}\left[\frac{\xi-\beta}{\xi}\right] \frac{w_{R}}{w_{L}} \widetilde{w}_{R}-\left(\frac{D_{L}}{I_{L}}-\frac{D_{H}}{I_{H}}\right) d t_{D} .
$$

In the case where we obtain a double dividend, $\tilde{w_{R}}<0$ and $d \tau_{H}<0$ : The decrease of labour taxes succeeds to reverse the sign of variation of the low-skilled outside option and the high-skilled labour supply. So the more $\beta>\xi$, the more frictions in the low-skilled labour market are initially important, and the more a decrease in labour tax rates reduces the unemployment rate and increases low-skilled welfare. Same reasoning for the labour productivity.

\section{Proposition 6}

Proof of Lemma: $\Delta_{\text {tot }}^{P P}(\gamma)-\Delta_{\text {tot }}^{P P}(\gamma=0)<0 \Leftrightarrow \frac{\partial \Delta_{\text {tot }}^{P P}}{\partial t_{L}}\left(d t-d t_{L}\right)>\frac{\partial \Delta_{\text {tot }}^{P P}}{\partial t_{H}}\left(d t_{H}-d t\right)$. We have $d t=$ $-\frac{G_{t_{D}}^{*}}{G_{t_{H}}^{*}+G_{t_{L}}^{*}} d t_{D} ; d t_{L}=-(1+\gamma) d a ; d t_{H}=-(1-\gamma) d a$; with $d a=\left(\frac{G_{t_{D}}^{*}}{(1-\gamma) G_{t_{H}}^{*}+(1+\gamma) G_{t_{L}}^{*}}\right) d t_{D}$. Using these 
definitions, we find: $\Rightarrow\left(\frac{d t_{H}-d t}{d t-d t_{L}}\right)=\frac{G_{t_{L}}^{*}}{G_{t_{H}}^{*}}$. Then

$$
\Delta_{t o t}^{P P}(\gamma)-\Delta_{t o t}^{P P}(\gamma=0)<0 \Longleftrightarrow \frac{\partial \Delta_{t o t}^{P P}}{\partial t_{L}}>\frac{G_{t_{L}}^{*}}{G_{t_{H}}^{*}} \frac{\partial \Delta_{t o t}^{P P}}{\partial t_{H}} .
$$

Proof of Proposition 6: Recall that:

$\Delta_{t o t}^{P P}=-\left[l I_{L}^{E}\left(\widetilde{w_{L}}-\frac{d t_{L}}{1-t_{L}}\right)+P_{Q}\left(V_{L}^{E}-V_{L}^{U}\right) d l+N H I_{H}\left(\widetilde{w_{H}}-\frac{d t_{H}}{1-t_{L}}\right)-D_{t o t} d t_{D}\right]$,

$\frac{\partial \Delta_{t o t}^{P P}}{\partial t_{L}}=-\left[l I_{L}^{E}\left(\frac{d w_{L}}{w_{L} d t_{L}}-\frac{1}{1-t_{L}}\right)+\left[l I_{L}^{E}\left(1-\frac{w_{R}}{w_{L}}\right)\right] \frac{d l}{l d t_{L}}+N H I_{H}\left(\frac{d w_{H}}{w_{H} d t_{L}}\right)\right]$,

$\frac{\partial \Delta_{\text {tot }}^{P P}}{\partial t_{H}}=-\left[l I_{L}^{E}\left(\frac{d w_{L}}{w_{L} d t_{H}}\right)+\left[l I_{L}^{E}\left(1-\frac{w_{R}}{w_{L}}\right)\right] \frac{d l}{l d t_{H}}+N H I_{H}\left(\frac{d w_{H}}{w_{H} d t_{H}}-\frac{1}{1-t_{H}}\right)\right]$.

If the substitution between the two types of labour is perfect, $\tilde{p_{L}}=\tilde{p_{H}}=\tilde{w_{H}}=0$. Replacing $\tilde{w_{L}}$ and $\tilde{l}$ with their expressions (Appendix B), we find $\frac{\partial \Delta_{t o t}^{P P}}{\partial t_{H}}=N H w_{H}$, and $\frac{\partial \Delta_{t o t}^{P P}}{\partial t_{L}}=l w_{L}\left(1+(\beta-\xi) \frac{w_{R}}{w_{L}}\right)$. By developing and replacing the derivatives $G_{t_{L}}^{*}$ and $G_{t_{H}}^{*}$ with their expressions obtained in Appendix F, we find the formula in the lemma $\frac{\partial \Delta_{t o t}^{P P}}{\partial t_{L}}>\frac{G_{t_{L}}^{*}}{G_{t_{H}}^{*}} \frac{\partial \Delta_{t_{o t} P}^{P P}}{\partial t_{H}} \Longleftrightarrow \frac{G_{t_{H}}^{*}}{\frac{\partial \Delta_{t o t}^{P P}}{\partial t_{H}}}>\frac{G_{t_{L}}^{*}}{\frac{\partial \Delta_{t o t}^{P P}}{\partial t_{L}}}$ is equivalent to:

$$
\begin{aligned}
& \left(1-\frac{\sigma t_{D}}{1+t_{D}}\right)-\frac{\eta_{H}}{1-t_{H}}\left[t_{H}+\frac{\sigma t_{D}}{1+t_{D}}\left(1-t_{H}\right)\right] \\
& >\left(1-\frac{\sigma t_{D}}{1+t_{D}}\right)\left(\frac{1}{1-t_{L}}\right)\left[\frac{\left(1-t_{L}\right) \xi w_{L}-B(1-\xi) \beta \frac{w_{R}}{w_{L}-w_{R}}}{w_{L}+(\beta-\xi) w_{R}}\right] \\
& +\left[t_{L}+\frac{\sigma t_{D}}{1+t_{D}}\left(1-t_{L}\right)\right]\left(\frac{1}{1-t_{L}}\right)\left[\frac{(1-\beta) \xi w_{R}-w_{L}(1-\xi) \beta \frac{w_{R}}{w_{L}-w_{R}}}{w_{L}+(\beta-\xi) w_{R}}\right]
\end{aligned}
$$

Because we assume a Laffer-efficent tax system, $G_{t_{L}}^{*}>0$. Moroever, $\frac{\partial \Delta_{\text {tot }}^{P P}}{\partial t_{L}}=l w_{L}\left(1+(\beta-\xi) \frac{w_{R}}{w_{L}}\right)>0$. Consequently, the right-hand side of the previous equation is always positive and depends negatively on $(\beta-\xi)$. The more $\beta>\xi$, the more frictions in the low-skilled labour market are initially important and the more an increase of low-skilled labour taxes is detrimental compared to an increase of high-skilled labour taxes. We can extract $\overline{\eta_{H}}$.

\section{J Robustness tests}

In Figure J.1, the range of the combinations $\left(\gamma, \eta_{H}\right)$ for which the progressive reform leads to a higher efficiency is represented for France. The curves stand for different level of $\gamma \in]-1 ; 1[$. On the $y$ axis, we represent $\triangle(\gamma)$, or the difference between $\Delta_{\text {tot }}^{P P}(\gamma)$ and $\Delta_{\text {tot }}^{P P}(\gamma=0)$.

At low values of $\eta_{H}$, redistributing all the revenue from the environmental tax to the low-skilled households $(\gamma=1)$ can be the best option. In contrast, when $\eta_{H}$ is higher, progressivity leads in all cases to inefficiency. The threshold appears to be slightly greater than 1.2. The range of the critical elasticity of the labour supply widens as the progressivity index increases. If the elasticity of the high-skilled labour 


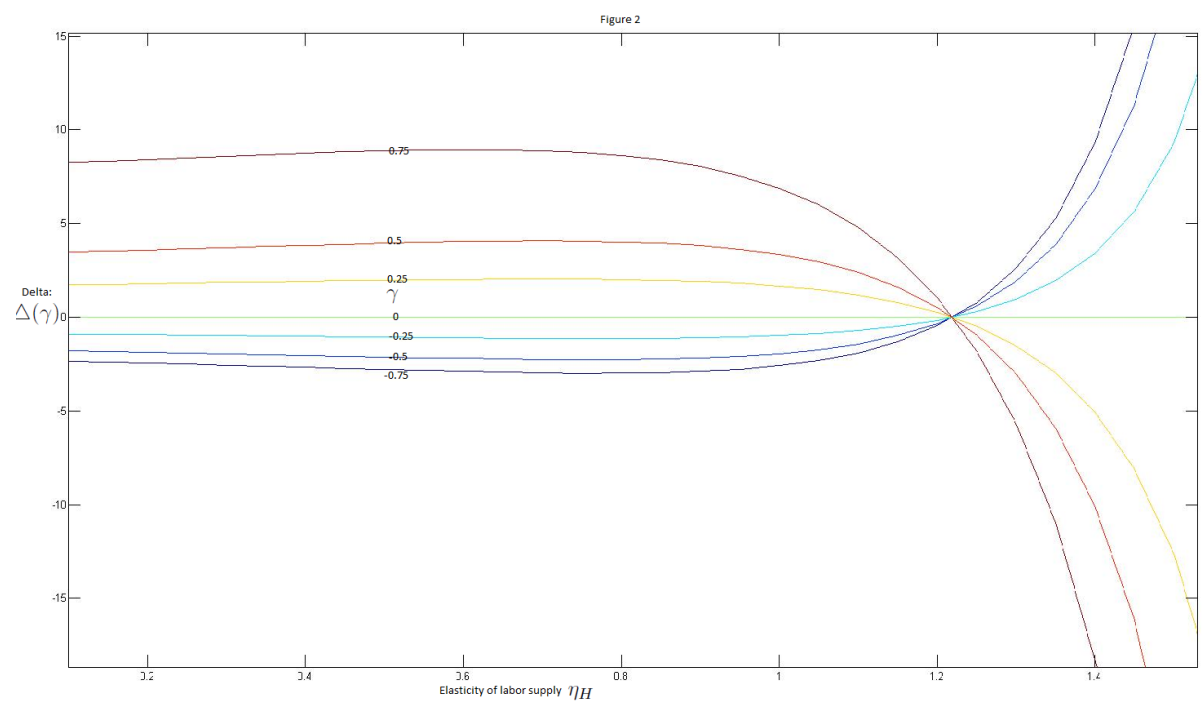

Figure J.1: Efficiency of progressive redistribution according to the elasticity of the high-skilled labour supply

supply is really high, it is not possible to avoid the trade-off between the efficiency and equality of the reform.

\section{Acknowledgments}

The authors thank Bas Jacobs, David Klenert, Roberton C. Williams III, Thomas Sterner, Frederick van der Ploeg, Guillaume Hollard, Charles Mason, Bruno Decreuse, Mouez Fodha, Emmanuelle Taugourdeau, two anonymous referees and the Associate Editor for helpful comments and suggestions. They are very grateful to conference participants at the IIPF (Dublin), EEA (Mannheim), EAERE (Helsinki), Unesco (Paris), and FAERE (Toulouse), and seminar participants at Erich-Schneider-Seminar (Kiel), CES-Ifo (Munich), PSE-CGDD (MEEM-Paris), and CREM (Rennes).

The usual disclaimers apply.

\section{Funding}

Financial support from the Investissements d'Avenir program of the French government (ANR-17-EURE001) is gratefully acknowledged. 


\section{References}

Arseneau, D. M. and Chugh, S. K. (2006). Ramsey meets hosios: the optimal capital tax and labor market efficiency. Technical report, Federal Reserve System.

Bayındır-Upmann, T. and Raith, M. G. (2003). Should high-tax countries pursue revenue-neutral ecological tax reforms? European Economic Review, 47(1):41-60.

Berry, A. (2019). The distributional effects of a carbon tax and its impact on fuel poverty: A microsimulation study in the french context. Energy Policy, 124:81-94.

Bovenberg, A. L. (1999). Green tax reforms and the double dividend: an updated reader's guide. International Tax and Public Finance, 6(3):421-443.

Bovenberg, A. L. and de Mooij, R. A. (1994). Environmental levies and distortionary taxation. The American Economic Review, 84(4):1085-1089.

Bovenberg, A. L. and van der Ploeg, F. (1996). Optimal taxation, public goods and environmental policy with involuntary unemployment. Journal of Public Economics, 62(1-2):59-83.

Bovenberg, A. L. and van der Ploeg, F. (1998). Tax reform, structural unemployment and the environment. Scandinavian Journal of Economics, 100(3):593-610.

Brückner, M. and Pappa, E. (2012). Fiscal expansions, unemployment, and labor force participation: Theory and evidence. International Economic Review, 53(4):1205-1228.

Cahuc, P., Carcillo, S., and Le Barbanchon, T. (2017). The effectiveness of hiring credits. IZA Discussion Paper 11248, Institute of Labor Economics (IZA), Bonn.

Cahuc, P., Marque, F., and Wasmer, E. (2008). A theory of wages and labor demand with intra-firm bargaining and matching frictions. International Economic Review, 49(3):943-972.

Callan, T., Lyons, S., Scott, S., Tol, R. S., and Verde, S. (2009). The distributional implications of a carbon tax in ireland. Energy Policy, 37(2):407-412.

Chetty, R., Guren, A., Manoli, D., and Weber, A. (2011). Are micro and macro labor supply elasticities consistent? a review of evidence on the intensive and extensive margins. American Economic Review, 101(3):471-75.

Chiroleu-Assouline, M. and Fodha, M. (2011). Environmental tax and the distribution of income among heterogeneous workers. Annals of Economics and Statistics/Annales d'Économie et de Statistique, pages $71-92$. 
Chiroleu-Assouline, M. and Fodha, M. (2014). From regressive pollution taxes to progressive environmental tax reforms. European Economic Review, 69:126-142.

Chung, J. W. (1994). Utility and production functions: theory and applications. Wiley-Blackwell.

Combet, E., Ghersi, F., Hourcade, J.-C., and Thubin, C. (2010). La fiscalité carbone au risque des enjeux d'équité. Revue française d'économie, 25(2):59-91.

Cremer, H., Gahvari, F., and Ladoux, N. (2003). Environmental taxes with heterogeneous consumers: an application to energy consumption in france. Journal of Public Economics, 87(12):2791-2815.

Cronin, J. A., Fullerton, D., and Sexton, S. E. (2017). Vertical and horizontal redistributions from a carbon tax and rebate. Working Paper 23250, National Bureau of Economic Research.

Deaton, A., Muellbauer, J., et al. (1980). Economics and consumer behavior. Cambridge university press.

Diamond, P. and Saez, E. (2011). The case for a progressive tax: from basic research to policy recommendations. Journal of Economic Perspectives, 25(4):165-90.

Diamond, P. A. (1982). Aggregate demand management in search equilibrium. Journal of Political Economy, 90(5):881-894.

Dissou, Y. and Siddiqui, M. S. (2014). Can carbon taxes be progressive? Energy Economics, 42:88-100.

Dolado, J., Motyovszki, G., and Pappa, E. (2018). Monetary policy and inequality under labor market frictions and capital-skill complementarity. IZA Discussion Paper 11494, Institute of Labor Economics (IZA), Bonn.

Dolado, J. J., Jansen, M., and Jimeno, J. F. (2008). On-the-job search in a matching model with heterogeneous jobs and workers. The Economic Journal, 119(534):200-228.

Douenne, T. (2018). The vertical and horizontal distributive effects of energy taxes. FAERE Working Paper 2018.10, French Association of Environmental and Resource Economists.

Ekins, P. (1997). On the dividends from environmental taxation. Ecotaxation, pages 125-162.

Fullerton, D. and Heutel, G. (2007). The general equilibrium incidence of environmental taxes. Journal of Public Economics, 91(3-4):571-591.

Fullerton, D. and Monti, H. (2013). Can pollution tax rebates protect low-wage earners? Journal of Environmental Economics and Management, 66(3):539-553.

Goulder, L. H. (1995). Environmental taxation and the double dividend: a reader's guide. International Tax and Public Finance, 2(2):157-183. 
Hafstead, M. A. and Williams, R. C. (2018). Unemployment and environmental regulation in general equilibrium. Journal of Public Economics, 160:50-65.

Heckman, J. J. (1993). What has been learned about labor supply in the past twenty years? The American Economic Review, 83(2):116-121.

Hungerbühler, M., Lehmann, E., Parmentier, A., and Van der Linden, B. (2006). Optimal redistributive taxation in a search equilibrium model. The Review of Economic Studies, 73(3):743-767.

Immervoll, H., Kleven, H. J., Kreiner, C. T., and Saez, E. (2007). Welfare reform in european countries: a microsimulation analysis. The Economic Journal, 117(516):1-44.

Jacobs, B. and de Mooij, R. A. (2015). Pigou meets mirrlees: On the irrelevance of tax distortions for the second-best pigouvian tax. Journal of Environmental Economics and Management, 71:90-108.

Jacobs, B. and van der Ploeg, F. (2019). Redistribution and pollution taxes with non-linear engel curves. Journal of Environmental Economics and Management.

Keuschnigg, C. and Ribi, E. (2009). Outsourcing, unemployment and welfare policy. Journal of International Economics, 78(1):168-176.

Klenert, D. and Mattauch, L. (2016). How to make a carbon tax reform progressive: The role of subsistence consumption. Economics Letters, 138:100-103.

Koskela, E. and Schöb, R. (1999). Alleviating unemployment:: The case for green tax reforms. European Economic Review, 43(9):1723-1746.

Koskela, E. and Schöb, R. (2009). Is tax progression good for employment? efficiency wages and the role of the prereform tax structure. FinanzArchiv: Public Finance Analysis, 65(1):51-72.

Kramarz, F. and Philippon, T. (2001). The impact of differential payroll tax subsidies on minimum wage employment. Journal of Public Economics, 82(1):115-146.

Laurent, E. (2011). Issues in environmental justice within the european union. Ecological Economics, 70(11):1846-1853.

Lehmann, E., Lucifora, C., Moriconi, S., and Van der Linden, B. (2016). Beyond the labour income tax wedge: the unemployment-reducing effect of tax progressivity. International Tax and Public Finance, $23(3): 454-489$.

Mathur, A. and Morris, A. C. (2014). Distributional effects of a carbon tax in broader us fiscal reform. Energy Policy, 66:326-334. 
Merz, M. (1995). Search in the labor market and the real business cycle. Journal of monetary Economics, $36(2): 269-300$.

Metcalf, G. E. (1999). A distributional analysis of green tax reforms. National Tax Journal, pages 655-681.

Metcalf, G. E. (2009). Designing a carbon tax to reduce us greenhouse gas emissions. Review of Environmental Economics and Policy, 3(1):63-83.

Parry, I. W. (1995). Pollution taxes and revenue recycling. Journal of Environmental Economics and Management, 29(3):S64-S77.

Petrongolo, B. and Pissarides, C. A. (2001). Looking into the black box: A survey of the matching function. Journal of Economic literature, 39(2):390-431.

Piketty, T., Saez, E., and Stantcheva, S. (2014). Optimal taxation of top labor incomes: A tale of three elasticities. American Economic Journal: Economic Policy, 6(1):230-71.

Pissarides, C. A. (1998). The impact of employment tax cuts on unemployment and wages; the role of unemployment benefits and tax structure. European Economic Review, 42(1):155-183.

Pissarides, C. A. (2000). Equilibrium unemployment theory. MIT press.

Poterba, J. M. (1991). Is the gasoline tax regressive? Tax Policy and the Economy, 5:145-164.

Proost, S. and Van Regemorter, D. (1995). The double dividend and the role of inequality aversion and macroeconomic regimes. International Tax and Public Finance, 2(2):207-219.

Rausch, S., Metcalf, G. E., and Reilly, J. M. (2011). Distributional impacts of carbon pricing: A general equilibrium approach with micro-data for households. Energy Economics, 33:S20-S33.

Røed, K. and Strøm, S. (2002). Progressive taxes and the labour market: Is the trade-off between equality and efficiency inevitable? Journal of Economic Surveys, 16(1):77-110.

Ruiz, N. and Trannoy, A. (2008). Le caractère régressif des taxes indirectes: les enseignements d'un modèle de microsimulation. Economie et Statistique, 413(1):21-46.

Saez, E. (2002). The desirability of commodity taxation under non-linear income taxation and heterogeneous tastes. Journal of Public Economics, 83(2):217-230.

Sato, Y. (2004). Migration, frictional unemployment, and welfare-improving labor policies. Journal of Regional Science, 44(4):773-793. 
Schneider, K. (1997). Involuntary unemployment and environmental policy: The double dividend hypothesis. Scandinavian Journal of Economics, 99(1):45-59.

Snower, D. (1996). The low-skill, bad-job trap. in Acquiring Skills, Cambridge: Cambridge University Press:pp.109-124.

Sørensen, P. B. (1999). Optimal tax progressivity in imperfect labour markets. Labour Economics, 6(3):435-452.

Sterner, T. (2012). Distributional effects of taxing transport fuel. Energy Policy, 41:75-83.

Stole, L. A. and Zwiebel, J. (1996). Intra-firm bargaining under non-binding contracts. The Review of Economic Studies, 63(3):375-410.

Strand, J. (2002). Effects of progressive taxes under decentralized bargaining and heterogeneous labor. International Tax and Public Finance, 9(2):195-210.

Summers, L. H. (2015). Demand side secular stagnation. American Economic Review, 105(5):60-65.

Terkla, D. (1984). The efficiency value of effluent tax revenues. Journal of Environmental Economics and Management, 11(2):107-123.

West, S. E. and Williams III, R. C. (2012). Estimates from a consumer demand system: implications for the incidence of environmental taxes. In Fuel Taxes and the Poor, pages 98-125. RFF Press.

Wier, M., Birr-Pedersen, K., Jacobsen, H. K., and Klok, J. (2005). Are co2 taxes regressive? evidence from the danish experience. Ecological Economics, 52(2):239-251.

Williams, R., Gordon, H., Burtraw, D., Carbone, J., and Morgenstern, R. (2015). The initial incidence of a carbon tax across income groups. Ecological Economics, 68(1):195-214. 